Document downloaded from:

http://hdl.handle.net/10251/60019

This paper must be cited as:

Bermúdez, V.; Luján, JM.; Piqueras, P.; Campos, D. (2014). Pollutants emission and particle behavior in a pre-turbo aftertreatment light-duty diesel engine. Energy. 66:509-522. doi:10.1016/j.energy.2014.02.004.

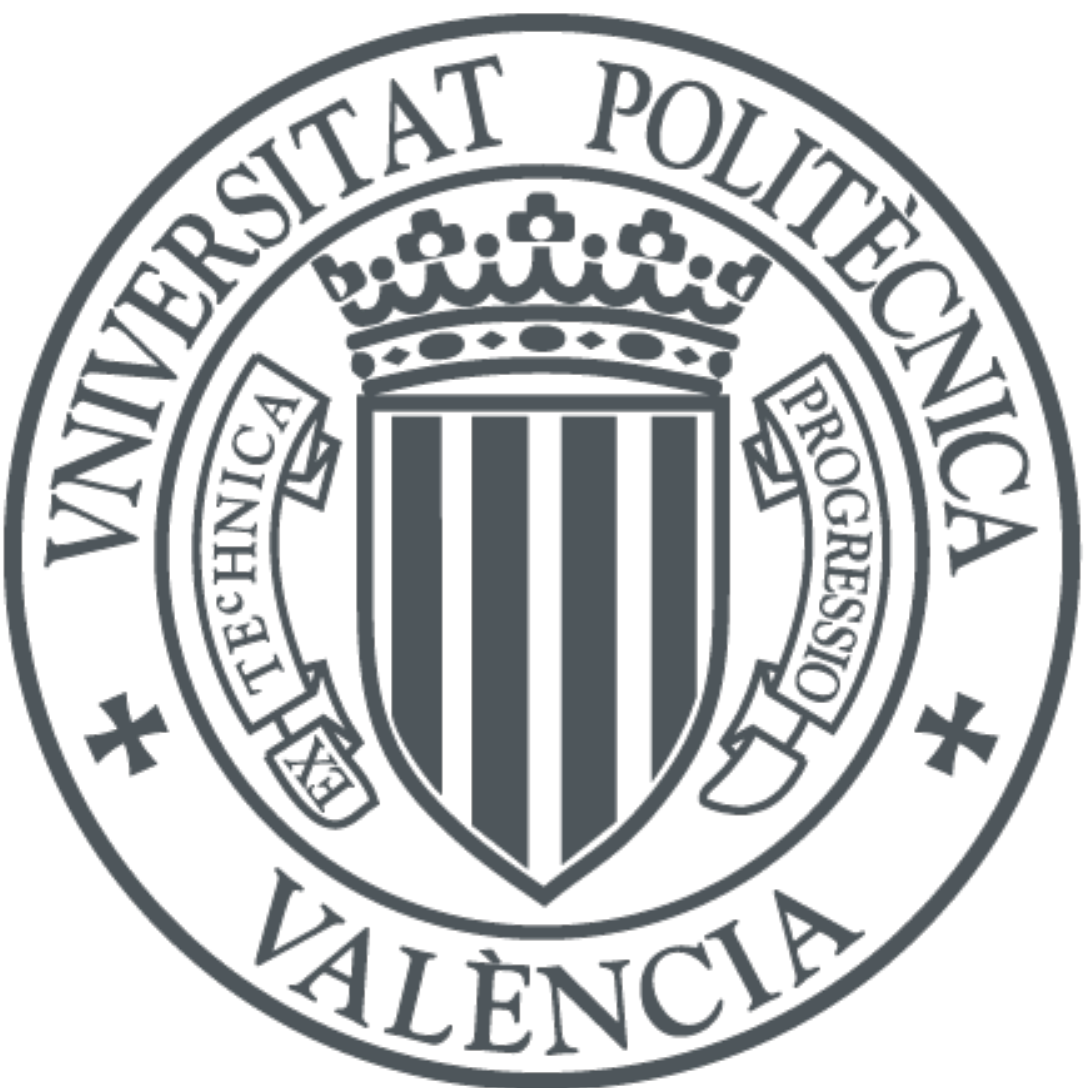

The final publication is available at

http://dx.doi.org/10.1016/j.energy.2014.02.004

Copyright Elsevier

Additional Information 


\title{
Pollutants emission and particle behavior in a pre-turbo aftertreatment light-duty diesel engine
}

\author{
Vicente Bermúdez *, José Manuel Luján, Pedro Piqueras, Daniel Campos \\ Universitat Politècnica de València, CMT-Motores Térmicos, Camino de Vera s/n, 46022 Valencia, Spain.
}

\begin{abstract}
Diesel particulate filters are a standard technology used in diesel engines in order to comply with actual and forthcoming regulations, regarding soot emissions and particulate matter in exhaust gases. In recent years, pre-turbo aftertreatment response has been investigated as opposed to the traditional aftertreatment location downstream from the turbine but just regarding engine performance. Previous studies do not deal in detail with gaseous and particle emission analisys in a pre-turbo aftertreatment configuration. This paper focuses on these topics. The gaseous pollutant and particle emissions have been assessed in a 4-cylinder, light-duty diesel EURO 4 engine typically used in European passenger car vehicles. Different steady-state operating points have been considered in order to extend the study over a wide range of operating conditions. Additionally, the New European Driving Cycle has been performed with the aim of reaching a comprehensive understanding of the aftertreatment dynamic response in terms of pollutant emissions. An increase in the amount of $\mathrm{NO}_{2}$ converted from $\mathrm{NO}$ and a reduction in emitted $\mathrm{CO}$ have been found at low load steady-state operating conditions with pre-turbo aftertreatment placement. In driving cycle conditions, a shift from nucleation to accumulation mode particles have been found, being the filtration efficiency scarcely affected. Keywords: Diesel engines, pre-turbo aftertreatment, pollutants emission, particle emission, DPF efficiency
\end{abstract}

\section{Introduction}

In the automotive sector, diesel engines are a major source of particulate matter (PM) and nitrogen oxides (NOx). It is well known that these pollutants are precursors for other chemical compounds, producing significant damage to the environment [1] and human health [2]. In recent years, different strategies have been developed to reduce pollutant emissions: exhaust gas recirculation (EGR) [3], common-rail injection [4], improvements in the fuel-air mixture process, optimized engine control [5], exhaust manifolds with improved heat transfer losses [6], etc. Owing to the application of the results obtained in these studies, and the progress carried out in the combustion process [7], a reduction has been achieved in the soot mass emitted by diesel engines. In addition, with the introduction of diesel particulate filters (DPF) in the aftertreatment systems of the exhaust gas, soot mass emission has reduced by about

\footnotetext{
*V. Bermúdez. CMT-Motores Térmicos, Universitat Politècnica de València, Camino de Vera s/n, 46022 Valencia, Spain. Phone: +34 963877650 Fax: +34 963877659 e-mail: bermudez@ mot.upv.es 
99\% [8]. However, a decrease in mass emission is not always accompanied by a reduction in particle emission. In this sense, the reduction in mass due to soot mass trapped at the DPF may be accompanied by an increase in the number of particles emitted with a size below $100 \mathrm{~nm}$. According to Setter et al. [9], a new conceptualization of particle size distribution shows an increase in particle numbers below $100 \mathrm{~nm}$ for the new generation of engines. These small particles can pass more easily through the DPF [10], so that an increase in total particle number at the DPF outlet has been observed. Furthermore, due to the detrimental effect on human airways that this type of particles can have [11], emission regulations are becoming increasingly stringent on this issue [12].

Nowadays, most DPFs are made of ceramic substrates with a honeycomb wall-flow structure. These systems are characterized by high filtration efficiency and low penalty in fuel consumption due to the active regeneration strategies that are carried out when the soot load inside the DPF reaches certain level [13]. In this regard, studies are mainly conducted to increase the maximum amount of ash that the DPF can tolerate [14], to better understanding on the pressure drop dynamics across this element [15], to analyse heat transfer phenomena [16], to the development of advanced catalytic materials [17], to the analysis of the soot filtration efficiency [18], or to study the relative position of the aftertreatment system with respect to the turbine [19].

Recently, some studies have attempted to find the optimal position of the aftertreatment system by varying the diesel oxidation catalyst (DOC) and DPF placement. Windsor et al. [20] propose that these be located at the cylinder outlet before the turbocharger. In turbocharged engines, the aftertreatment system is traditionally placed downstream from the turbine, with the DOC upstream of the DPF. This configuration uses the $\mathrm{NO}_{2}$ produced in the DOC for further oxidation of particulate matter in the DPF. Placing the aftertreatment system upstream from the turbine offer certain advantages such as clean high pressure EGR. In this sense, the pre-turbo aftertreatment approach ensures that the exhaust gas first passes through the DPF, and it is then recirculated into the intake manifold before passing through the turbocharger. It provides a soot-free exhaust gas to the high pressure EGR system thus the durability of the elements of this system is increased [21]. Other advantages of the pre-turbo aftertreatment configuration are the high temperatures reached at the DPF inlet, which can serve to promote passive regenerations and reduce time up to DOC light-off [22]; and the pressure drop reduction along the aftertreatment system due to the higher gas density [23]. On one hand, this effect leads to fuel savings because it mitigates the increase of exhaust back-pressure especially when soot accumulation within the DPF increases [24]. On the other hand, an additional reduction in fuel consumption is obtained due to the reduction of active regenerations required to clean the DPF [25].

\section{Experimental setup}

The measurements were carried out in the exhaust aftertreatment system of a 2.0 L, 4-cylinders, high-speed direct injection (HSDI) turbocharged diesel engine for passenger car application which complies with EURO 4 standards. Further detailed specifications of the engine characteristics and the aftertreatment system used are given in Table 1 and Table 2. The engine was installed in a fully equipped test cell with all the auxiliary devices required for appropriate 
engine operation and control. The test cell was designed using the criteria detailed by Martyr and Plint [26]. Regarding engine fuel, ultralow sulfur diesel (USLD) has been used in all the test being its properties shown in Table 3.

The test bench was equipped with a $250 \mathrm{~kW}$ asynchronous dynamometer SHENCK®Dynas Li250, which allows instant engine speed and torque control. In order to perform modifications to the engine operating parameters, the ETASßINCA software was used to modify the engine calibration in an engine control unit (ECU). K type thermocouples and KISTLER $囚 4045 A 5$ piezoresistive sensors with the original cooler adaptor, whose main characteristics are shown in Table 4, were suitably located in the intake and exhaust zones of the engine. Fuel consumption was determined by two systems. The first consists of a fuel gravimetric system with an AVL®733S Dynamic Fuel Meter. The measurement device consists of a measuring vessel filled with the fuel and suspended on a balance system. Fuel consumption values are obtained by calculating the vessel's weight loss over time. Since the response time of this system might possibly be too long for measurement under transient operation, the fuel consumption signal provided by the ECU was calibrated in steady-state operating conditions. After calibration, the ECU was used as a second fuel consumption measurement system [27]. The Sensyflow®P Sensycon hot-plate anemometer system was used to measure the flow rate of the intake air mass. The measurement range of the anemometer is $0-720 \mathrm{~kg} / \mathrm{h}$.

Different equipment has been used in this study for measuring particle and pollutant emissions. For particle measurement, a TSI $囚 E E P S$ (Engine Exhaust Particle Sizer) Spectrometer has been employed in order to obtain fast response particle measurements during dynamic cycles [28]. EEPS is capable to measure particle size distribution at a sample-rate of up to $1 \mathrm{~Hz}$ and providing a measurement range between 5.6 to $560 \mathrm{~nm}$. A valve system was installed in order to provide measurements upstream and downstream of the DPF in steady-state conditions and allow filtration efficiency calculation.

A similar valve system concept was installed to assess the DOC conversion during the steady-state operating points. In this case, a HORIBA®Mexa 6000 F-TIR analyzer was used to provide a figure of unregulated pollutant emissions. Finally, an HORIBA®Mexa 7100 DEGR was installed at the end of the exhaust line downstream of the aftertreatment to measure tailpipe emission of regulated pollutants. Figure 1 shows the experimental setup for this study.

\subsection{Operating mode}

Extensive experimental work has been carried out in order to assess the effect of aftertreatment system placement in the exhaust line in terms of gaseous pollutants and particle emissions. The study was conducted comparing the pre-turbo aftertreatment configuration versus the post-turbo aftertreatment configuration (traditional). The original post-turbo aftertreatment configuration is composed of a close-coupled DOC followed by underfloor DOC and DPF. In the case of the pre-turbo aftertreatment configuration, the underfloor DOC and DPF are placed upstream of the turbine being the close-coupled DOC removed in this configuration.

In order to assess a wide range of different engine behavior, different steady-state operating points and dynamic tests were performed. As shown in Figure 2, five engine operating modes have been selected from the New European 
Driven Cycle (NECD) for passenger cars. The selection criteria of these points were the flatlands occurring during the NEDC cycle. Thus, these points remain stable for 3 seconds, except $\mathrm{K}$ point, which is located on the first acceleration ramp in the EUDC (Extra Urbad Driving Cycle). These points have different engine speed, load, EGR rate and SOI (Start of Injection), in order to obtain a representative range of the engine emission. Table 5 shows the main characteristics of the selected points.

\subsection{Particle measurement method}

The methodology used to measure the particle size distribution in transient conditions, which is also applicable to steady-state conditions, is performed in the laboratory according to Desantes et al. methodology [29], which is sketched in Figure 3.

The dilution system used for this study was a Dekati@Fine Particle Sampler FPS-4000 [30]. This system dilutes the sample in two stages. A porous tube (PTD) is used as the primary diluter, and subsequent an ejector diluter (ED) carries out as the secondary dilution (hot dilution + cold dilution), as shown Figure 3 from stage $\mathrm{A} \rightarrow \mathrm{B}$ and $\mathrm{B} \rightarrow \mathrm{C}$ ways. The particles within the size range of 10-50 $\mathrm{nm}$ are very unstable and are significantly affected by the dilution temperature due to the fact that they consist of a solid core that contains some volatile fractions. In this sense, the dilution ratio affects gas-to-particle conversion phenomena through the nucleation and adsorption of the soluble organic fractions (SOF) on the soot [31] or the supersaturate vapor condensation [32].

\section{Results and discussion}

Firstly, the assessment of the different partial steady-state operating points selected from the NEDC cycle was carried out. For this task, samples of the exhaust gas were taken after a given period of engine stabilization in order to guarantee a steady thermal and fluid dynamic state in each test. To ensure that the analyzed steady-state operating conditions were the same in both post-and pre-turbo aftertreatment configurations, tests were carried out at iso-torque conditions and with constant intake manifold pressure. Figure 4 shows some of the control variables measured in different configurations. The gaseous emission measurement was performed upstream and downstream from the DOC, while the particle measurement was carried out upstream and downstream from the DPF.

\subsection{Gaseous emission. Steady-state operating points.}

- Nitrogen Oxides: $\mathrm{NO}, \mathrm{NO}_{2}$ and $\mathrm{NOx}$

Firstly, Figure 5.A shows that total NOx at both DOC inlet and outlet are practically invariant. However, when the analysis is focused on each compound separately ( $\mathrm{NO}$ and $\left.\mathrm{NO}_{2}\right)$, which are shown in Figure 5.B and Figure 5.C, components of total NOx do not remain invariant but there are significant variations.

On one hand, Figure 4 shows that the EGR rate is slightly lowered in a pre-turbo configuration in the case of $\mathrm{K}$ and Q operating points with respect to post-turbo aftertreatment configuration, but the air to fuel ratio (AF) is 
similar. It causes an increase of $\mathrm{NO}$ and a decrease of $\mathrm{NO}_{2}$ at the DOC inlet due to the higher density of the air in the intake manifold induced by the lower EGR rate. On the other hand, the DOC outlet shows a decrease in $\mathrm{NO}$ and an increase in $\mathrm{NO}_{2}$, stronger in the pre-turbo than post-turbo configuration. As the conversion ratio of $\mathrm{NO}$ to $\mathrm{NO}_{2}$ is strongly dependent on temperature, one can say that it was caused by the DOC inlet temperature, which at the pre-turbo configuration is higher because it is located upstream of the turbine and the expansion process has not occurred yet.

- Ammonia $\left(\mathrm{NH}_{3}\right)$, sulfur dioxide $\left(\mathrm{SO}_{2}\right)$ and dinitrogen oxide $\left(\mathrm{N}_{2} \mathrm{O}\right)$.

The concentrations of these pollutants are negligible. Since the sulfur content in the fuel is less than $10 \mathrm{ppm}$, as mandated by the Spanish law, sulfur dioxide formation is negligible. Ammonia is usually present when SCR (Selective Catalytic Reduction) aftertreatment systems are used [33], using urea as an additive for $N O x$ reduction reaction but this is not the case in the present study. $\mathrm{N}_{2} \mathrm{O}$ emission is affected by the presence of $\mathrm{NH}_{3}$ and $\mathrm{HCN}$. Some results show that the presence of $\mathrm{NH}_{3}$ helps in the conversion of $\mathrm{NO}$ to $\mathrm{N}_{2} \mathrm{O}$, whereas $\mathrm{HCN}$ acts as the activating source of $\mathrm{N}_{2} \mathrm{O}$ formation [34]. This compound has only relevance when the SCR system is used, so that its emission is not present as in the case of the ammonia.

- Carbon monoxide $(\mathrm{CO})$ and total hydrocarbons $(\mathrm{THC})$

Carbon monoxide is a very harmful compound to human health, thus any reduction is advantageous for the environment. $C O$ emissions occur due to non-complete combustion, and $C O$ emissions are strongly linked with THC emissions, since both are results of low quality combustion.

Figure 6.A shows that $\mathrm{CO}$ emissions at the DOC inlet are similar in both configurations of the exhaust line. When it is measured downstream from the DOC, there is a very significant reduction at the $\mathrm{F}$ and $\mathbf{J}$ points in the case of the pre-turbo aftertreatment architecture. In this oxidation catalyst, the activation temperature is approximately $150^{\circ} \mathrm{C}$. These two steady-state operating points do not reach this temperature level in the traditional post-turbo aftertreatment placement, so an increase of the DOC inlet temperature at these conditions brings a very pronounced decrease in the amount of $C O$ emitted to the atmosphere.

Concerning THC emission, only DOC outlet data are available due the fact that HORIBA®MEXA 7100 was installed at the end of the exhaust line, and HORIBA@6000 F-TIR cannot provide $T H C$ results. Figure 6.B shows the results for THC DOC outlet emission with a similar trend than that obtained with $C O$.

- Light hydrocarbons (<7 Carbon atoms)

During the combustion process in diesel engines, the fuel does not mix completely with the required oxygen to burn the total amount of fuel. Unburned hydrocarbons are emitted as a result of the incomplete combustion process, in which part of the fuel is not oxidized. Figure 7 only shows the concentration of methane $\left(\mathrm{CH}_{4}\right)$ and iso-butene (iso $-\mathrm{C}_{4} \mathrm{H}_{8}$ ), as measured concentration of other hydrocarbons analyzed (ethylene $\left(\mathrm{C}_{2} \mathrm{H}_{4}\right)$, 
ethane $\left(C_{2} H_{6}\right)$, propylene $\left(C_{3} H_{6}\right), 1.3$ Butadiene $\left(1,3-C_{4} H_{6}\right)$, n-Butane $\left(n-C_{4} H_{10}\right)$, benzene $\left(C_{3} H_{6}\right)$ and toluene $\left.\left(\mathrm{C}_{7} \mathrm{H}_{8}\right)\right)$ are negligible and below the analyzer error $(2 \mathrm{ppm})$. In this case, methane shows a flat trend emission despite the steady-state operating point performed. The iso-butene variations in different steady-state operating conditions demonstrate that the highest levels of hydrocarbons occur at low load and low speed. In such operating conditions, the combustion efficiency is lower because the too lean mixture damages flames stability in last stages of the injection process.

\subsection{Steady-state operating points. Particle emission.}

This section evaluates the change produced by the aftertreatment placement in terms of particle emissions. As shown in Figure 4, the engine performance is similar in pre-turbo and post-turbo aftertreatment configuration. Proof of this are the particle size distributions upstream of the DPF are practically the same independently on the exhaust line architecture, as shown in Figure 8.

When the DPF inlet particle emission is evaluated in detail by separating the nucleation and the accumulation mode [35], a reduction is observed in the pre-turbo aftertreatment configuration both in accumulation and nucleation modes.

Usually, the particle size grows along the exhaust line, mainly due to agglomeration and aggregation phenomena. These processes cause the growth of the particles due to the temperature drop along the exhaust system. It is related to the heat transfer losses taking placed in the different elements placed in the exhaust line [36]. Figure 9 shows the temperature drop in each element of the aftertreatment architecture as a function of the steady-state operating point. Figure 9 clearly shows that in pre-turbo configuration the aftertreatment temperature is higher than in the postturbo aftertreatment. Due to the fact that the turbine uses large amount of the exhaust gas energy [24], the largest temperature drop occurs in the expansion process. Therefore, the temperature at the aftertreatment system inlet with pre-turbo architecture is much higher than in post-turbo aftertreatment configuration. It contributes to avoid adsorption and condensation phenomena in the pre-turbo configuration under steady-state operation.

On one hand, the raw emission of particles comprising the accumulation mode, which are those with $\mathrm{Dp}>30 \mathrm{~nm}$, are reduced in the pre-turbo aftertreatment configuration (Figure 10.A). This reduction in the accumulation mode and the significant decrease occurring in the nucleation mode suggests that some particles finish their formation along the exhaust line in the post-turbo aftertreatment configuration but this does not happen in the pre-turbo aftertreatment configuration because of the shorter path up to the DPF [37]. On the other hand, homogenous nucleation occurs when enough free energy exists in the vapor to form a new spherical cluster. The nucleation can be modeled by the RKC (Reiss-Katz-Cohen) theory [38]. This theory states that the nucleation rate of supersaturated vapor is given by: 


$$
\begin{aligned}
J= & \frac{a}{\rho} \sqrt{\left(\frac{2 N_{A}^{3} \sigma M}{\pi}\right)}\left(\frac{S P_{e}}{R T}\right)^{2} \\
& \exp \left[\frac{-16 \pi N_{A}}{3(\ln S)^{2}}\left(\frac{M}{\rho}\right)^{2}\left(\frac{\sigma}{R T}\right)^{3}\right]
\end{aligned}
$$

In equation (1), $J$ is the rate of nucleation, $N_{A}$ is the Avogadro's number, $P_{e}$ is the equilibrium vapor pressure, $T$ is the gas temperature, $M$ represents the molecular weight of the vapor, $\rho$ is the liquid density, $\sigma$ is the surface tension, $R$ is the gas constant, $a$ is the condensation coefficient and $S$ is the supersaturation, which is defined as $S=P / \mathrm{P}_{\mathrm{e}}$, being $P$ the local pressure.

Pressure and temperature of the exhaust gas at DPF inlet are higher in the pre-turbo than in the post-turbo aftertreatment configuration, as shown in Figure 9. An increase in these two variables establishes a reduction in the nucleation rate as it can be concluded from Figure 10.A. In the case of the post-turbo aftertreatment placement, the adsorption and condensation phenomena of organic compounds of high molecular weight, such as unburned hydrocarbons, oxygenated hydrocarbons or polycyclic aromatic hydrocarbons, cause an overall increase of the particles diameter and also the generation of new particles, according to the sketch shown in Figure 11. However, these phenomena are not taking place in the pre-turbo aftertreatment configuration under steady-state operation, since the particles perform a shorter route in the exhaust line in comparison to the post-turbo aftertreatment configuration. Consequently the nucleation mode particles may be not still formed passing across the DPF shaped as hydrocarbons. Hence the overall balance shows a reduction in cores percentage in the pre-turbo aftertreatment configuration (Figure 10.B) and an increase of the geometric mean diameter (GMD) in particle size distribution (Figure 10.C) with respect to the post-turbo aftertreatment configuration.

The particle size distribution at DPF outlet vary much more than at DPF inlet between both aftertreatment configurations. Nevertheless, the filtration efficiency, which is shown in Figure 12, is very high in both configurations and inside the well-known characteristics of wall-flow DPFs, being the minimum measured value at discrete diameters in 97\%. At first glance, as filtration efficiency indicates, the DPF acts similarly in both configurations in a range between 20 and $150 \mathrm{~nm}$. In contrast, the DPF filtration efficiency suffers a decrease for particles smaller than $20 \mathrm{~nm}$ in the pre-turbo aftertreatment configuration in most operating points. The reason can be found in the passive regeneration process according to Beatrice et al. [39]. To verify the occurrence of passive regeneration the DPF is weighed before and after the sequential testing of the steady-state operating points. In this regard, a reduction of the weight of the DPF in pre-turbo placement with respect to the traditional post-turbo configuration has been found.

Lastly, in the low load operating points F, J, and L (engine load below 10\%), there is also a significant decrease in filtration efficiency in the range between $150 \mathrm{~nm}$ and $180 \mathrm{~nm}$ [40] in the case of the pre-turbo aftertreatment configuration. Since the most penetrating particle size seems to be located at a smaller size, this result may be related to measurement uncertainty in this operating region, since the filtration efficiency in operating points $\mathrm{K}$ and $\mathrm{Q}$ (engine load from $21 \%$ to $25 \%$ ) is identical. 


\subsection{New European Driving Cycle. Gaseous emission.}

Two types of tests have been performed for this cycle. On one hand, the first comprises the evaluation of the aftertreatment position in terms of pollutant limits dictated by the European standards [12]. In order to do that, a cold NEDC was tested for both exhaust line configurations and was compared concerning the approval of regulated gaseous pollutants. This kind of test allows assessing the position of the aftertreatment system, showing variables like the influence of warm-up engine strategy or DOC light-off. On the other hand, NEDC cycles were tested in order to provide a comprehensive baseline for unregulated pollutants and particles emission analysis when the aftertreatment placement is varied.

- Nitrogen oxides $\left(\mathrm{NO}, \mathrm{NO}_{2}\right.$ and $\left.\mathrm{NOx}\right)$.

The overview of Figure 13 points out that the total accumulated NOx is slightly higher in the pre-turbo aftertreatment configuration than in the post-turbo aftertreatment configuration. As Table 6 shows, both aftertreatment configurations are fulfilling EURO 4 regulation concerning NOx emissions.

On one hand, DOC inlet NOx emission is slightly decreased during UDC (Urban Driving Cycle) cycles when the pre-turbo aftertreatment configuration is evaluated (Figure 13.A). This behavior is due to the fact that the EGR valve is slighty open in order to keep the intake manifold pressure at the same level as in the case of the post-turbo aftertreatment configuration. This response reduces the fresh air mass and consequently decreases NOx, specially in these stretches. On the other hand, when EUDC (Extra Urban Driving Cycle) emission was analyzed, an increase in total NOx mass at the end of NEDC was observed.

From the point of view of $N O$ concentration, the higher EGR rate during UDC has driven to $N O$ reduction at the inlet of the DPF in pre-turbo aftertreatment configuration. (Figure 13.C). A drop by almost half in the NO concentration at the DOC outlet is observed in Figure 13.D in also in the case of the pre-turbo aftertreatment configuration. It is also interesting worth highlighting the fact that the $\mathrm{NO}$ to $\mathrm{NO}_{2}$ conversion rate are greater in the case of pre-turbo placement of the aftertreatment (40\% conversion in the pre-turbo configuration vs. $8 \%$ conversion in the post-turbo configuration), as is shown in Figure 13.F. As explained in Section 3.1, the DOC conversion rate is determined by the temperature of the exhaust gas. The higher the temperature is, the higher the conversion rate. Observing the DOC inlet temperature behavior, there was an increase in the preturbo aftertreatment configuration since the exhaust gas does not pass through the turbocharger before the DOC. Therefore, it is avoided the temperature drop that the flow undergoes in the turbine expansion.

- Ammonia $\left(\mathrm{NH}_{3}\right)$, sulfur dioxide $\left(\mathrm{SO}_{2}\right)$ and dinitrogen oxide $\left(\mathrm{N}_{2} \mathrm{O}\right)$.

As stated in Section 3.1, the emission of these unregulated contaminants during steady-state operating points are negligible. Nevertheless, the emission of these compounds may occur during a transient operation so that its evaluation during NEDC is advised. Figure 14 shows results at the DOC inlet in the case of pre-turbo aftertreatment configuration. It confirms also for transient operation the low emission for these pollutants, 
showing values under the analyzer error (2 ppm). In this sense, it is not possible to extract any conclusion about them, since they are emitted in a very low concentration.

- Carbon monoxide $(C O)$ and Total hydrocarbons $(T H C)$.

During NEDC it can be observed that with a pre-turbo aftertreatment configuration there is a decrease in carbon monoxide and hydrocarbons emission at the DOC outlet. Regarding $C O$ (Figure 15.A) and THC (Figure 15.B), both compounds show a similar trend, being different the oxidation rate between $C O$ and $T H C$. In the pre-turbo aftertreatment configuration, the DOC placement leads to reduce the required time to reach the DOC light-off (at $150^{\circ} \mathrm{C}$ ). This allow a reduction of $11 \%$ in $C O$ and a reduction of $2 \%$ in $T H C$ emitted when pre-turbo aftertreatment configuration is tested, as shown Table 6.

- Light hydrocarbons ( $>7$ Carbon atoms)

Unregulated light hydrocarbons emission have some relevance in terms of quantity. The pollutants analyzed in Figure 16 are methane $\left(\mathrm{CH}_{4}\right)$, ethylene $\left(\mathrm{C}_{2} \mathrm{H}_{4}\right)$, propene $\left(\mathrm{C}_{3} \mathrm{H}_{6}\right)$, iso-butene $\left(i s o-\mathrm{C}_{3} \mathrm{H}_{6}\right)$ and benzene $\left(\mathrm{C}_{6} \mathrm{H}_{6}\right)$. Other compounds are not taken into account in the study since the measurement is within the analyzer error $(2$ $\mathrm{ppm})$.

Methane $\left(\mathrm{CH}_{4}\right)$, whose emission is shown in Figure 16.A, is a greenhouse gas which remains in the atmosphere for 9-15 years [41]. Methane may be appearing due to thermal cracking of paraffins and olefins. Thermal cracking occurs when a long-chain paraffinic bond is broken and consequently separated into two pairs of paraffins and olefins [42]. In the pre-turbo aftertratment configuration, the DOC inlet temperature is higher than in the post-turbo aftertreatment configuration assisting thermal cracking and promoting $\mathrm{CH}_{4}$ emission. Olefins like $C_{3} H_{6}$, shown in Figure 16.B, have a strong tendency to split into like $C_{2} H_{4}$, which explains the increase in ethylene emission, as it can be observed in Figure 16.C. The change in iso-butene (iso- $\mathrm{C}_{3} \mathrm{H}_{8}$ ) emission, which is represented in Figure 16.D, shows the same trend like that under steady-state operation, showing a constant emission level during whole NEDC.

Focusing on benzene $\left(\mathrm{C}_{6} \mathrm{H}_{6}\right)$, which is an polyciclic aromatic hydrocarbon (PAH), is one of the most harmful compounds to human health due to its carcinogenic effect. Recent studies have shown the difficulty in oxidizing benzene in a DOC [43]. Taking into account such a difficulty, it is expected that most of the TLHC emission, shown in Figure 17, are due to benzene contribution. It is confirmed by the benzene tailpipe emission, also shown in Figure 16.E. In fact, as raw benzene emission is the same whatever the aftertreatment placement, the lower catalytic surface in pre-turbo placement is damaging the benzene conversion efficiency. Considering the raw emission of lighter hydrocarbons and the tailpipe $T L H C$ trend, these must have higher conversion efficiency in pre-turbo placement; i.e. due to the fact that they are lighter the temperature increase in pre-turbo placement is dominating on dwell time. 


\subsection{New European Driving Cycle. Particle emission.}

From a general point of view, both aftertratment configurations fulfill the future EURO 6 particle number limit despite of the EURO 4 engine calibration. The particle emission does not exceed $2.10^{11} \# / \mathrm{km}$ in any event, clearly lower than the EURO 6 limit set at $6.10^{11} \# / \mathrm{km}$.

As explained in Section 2.2, a very important factor when the particle measurement is carried out is the temperature at which the sampled exhaust gas is diluted with the primary dilution air [29]. Another factor of influence in particle size distribution measurement is the dilution ratio required to condition the sample at the spectrometer inlet. In this case, as shown in Figure 18, dilution ratios (DR) vary depending on both sampling point, upstream or downstream of the DPF, and on the aftertreatment configuration. This occurs because the pressure at the DPF inlet varies with the analyzed configuration. The dilution system employed works by pressure difference between the sample inlet and the pressure that reaches the diluted sample due to the suction taking place in the secondary dilution. As a consequence, greater sample pressure is reflected in a smaller dilution ratio. In the pre-turbo configuration, the gases passing through the DPF have a higher pressure than in the post-turbo configuration, since they have not undergone the expansion process occurring across the turbine. In any case, the dilution ratio was selected at the beginning of the cycle (at idle), being 170: 1 for the post-turbo aftertreatment configuration, and 100: 1 for the pre-turbo aftertreatment configuration at the DPF inlet.

When the measurement is carried out downstream of the DPF, it is not possible to establish high dilution ratios, since the intrinsic low particle concentration of the sample makes it hardly detectable by the spectrometer if the sample is diluted. Therefore, the dilution ratio applied was the maximum possible ensuring that the sample could be detected by the EEPS. The dilution ratio was set to $8: 1$ for the post-turbo aftertreatment configuration and to $2: 1$ in the case of pre-turbo DPF placement.

As seen previously, there is a slighly increase in hydrocarbons at the DPF inlet in the case of the pre-turbo aftertreatment configuration in comparaison with the post-turbo aftertreatment configuration. This behavior is also seen in the nucleation particle mode (Dp<30 nm), shown in Figure 19.A for DPF inlet, which are the particles whose formation is closely linked to hydrocarbons. However the accumulation particle mode ( $\mathrm{Dp}>30 \mathrm{~nm})$ and the total particles remain at the same level in both configurations, as Figure 19.C and Figure 19.D show.

During the particle transport along the particle measurement line, it may occur that certain nucleation particles were generated due to nucleation of hydrocarbons. Figure $20(A \rightarrow B \rightarrow D$ way), which shows the phase diagram in the dilution system, points out that the particles remain within the two steps of the dilution system in the pre-turbo aftertreatment configuration. A larger quantity of hydrocarbons present in the exhaust gas ( $Y$ axis in Figure 20), and a higher exhaust temperature (X axis in Figure 20) at DPF inlet favour thermochemical processes comprising the adsorption-nucleation phenomena of hydrocarbons in the secondary stage of dilution (ED at Figure 3). Due to this fact, some particles detected by the spectrometer are actually hydrocarbon formed by condensation. The combination of the increase in hydrocarbons and particle growing phenomena are the reason for the increase in the nucleation mode at the DPF inlet pre-turbo configuration. 
However, when comparing pre-turbo versus post-turbo aftertreatment configurations at the DPF outlet, a decrease can be observed in nucleation particle mode and an increase in accumulation particles mode. The increase in accumulation mode downstream of the DPF is due to the thermal gradient between exhaust gas and ceramic wall temperature. In this sense, during the NEDC assessed with the pre-turbo aftertreatment configuration, the temperature inside the DPF outlet channels was cold so coagulation of certain nucleation particles mode present at DPF inlet was expected. As a consequence of coagulation of nucleation particles mode at DPF outlet, a decrease in nucleation particles mode measurement was observed.

Although an increase in passive regeneration process and an increase in nucleation mode at DPF outlet was found under steady-state conditions, there is no similar trend during NEDC. This is due to the fact that the nucleation rate during transient operation at the DPF outlet in pre-turbo configuration is much lower than in the post-turbo aftertreatment configuration because of the shift to accumulation mode. In this sense, although passive regeneration is favored and consequently an increase in nucleation mode would be expected, the overall balance between passive regeneration event and particles size growth due to ligh-hydrocarbons condensation leads to a reduction in the nucleation mode particles number emitted. One can say that the reduction in this particle mode is a clear advantage due to the fact that these particles are the most harmful to human health.

\section{Summary and conclusions}

The experiments performed in this work have been carried out in a EURO 4 passenger car engine considering post-turbo and pre-turbo aftertreatment placements. The original post-turbo aftertreatment configuration is composed of a close-coupled DOC and underfloor DOC and DPF. In the case of the pre-turbo aftertreatment configuration the underfloor DOC and DPF are placed upstream of the turbine removing the close-coupled DOC. Firstly, the pollutant emissions and the DPF filtration efficiency have been assessed in five steady-state operating points. After presenting the most relevant conclusions under steady-state conditions, the main results on engine performance during NEDC has been highlighted.

\subsection{Steady-state operating points}

- In terms of nitrogen oxides, it should be noted that placing the aftertreatment system in pre-turbo location has not shown effects in total $\mathrm{NOx}$ emission. In contrast, when $\mathrm{NO}$ and $\mathrm{NO}_{2}$ compounds are analyzed separately, an increase in $\mathrm{NO}_{2}$ at the DOC outlet at low load operating points is obtained. The reason is the increased ratio of $\mathrm{NO}$ to $\mathrm{NO}_{2}$ conversion, favored by the higher temperature at the inlet of the DOC. This is advantageous because it contributes, together with higher temperature upstream the DPF, to $\mathrm{NO}_{2}$ passive regeneration leading to extend the time between active regenerations events. This is translated in fuel savings because of the decrease in both DPF average soot load and regeneration events frequency.

- An increased $C O$ and $T H C$ oxidation ratio in the low load steady-state operating points has been found in the pre-turbo aftertreatment configuration. 
- The light hydrocarbon emissions remained virtually unchanged irrespective of the aftertreatment system position, being the analyzed experimental values at the same level in both configurations.

- Concerning particles measurement; nucleation particle emission, smaller in size, is reduced at the DPF inlet in the case of the pre-turbo aftertreatment configuration due to the fact that these particles were never being formed upstream the DPF+VGT configuration. Contrarily, a slight increase of this mode emission appears at the VGT outlet due to the effect of the passive regeneration process.

\subsection{Dynamic cycles. NEDC}

- In the same way under steady-state operating points, there is much more $\mathrm{NO}_{2}$ available for DPF passive regeneration in pre-turbo aftertreatment placement due to the higher DOC inlet temperature during the NEDC, leading to higher $\mathrm{NO}$ to $\mathrm{NO}_{2}$ conversion rate.

- In terms of regulated pollutants, there is a decrease in both $C O$ and $T H C$ emission during NEDC because the positive effect of the higher DOC inlet temperature leading to a faster DOC light-off.

- Concerning particle emission, both aftertreatment architectures fulfill next future EURO 6 legislation with an engine calibration for EURO 4, as the emission limit is $6.10^{11} \# / \mathrm{km}$ and in any event an emission of $2.10^{11} \# / \mathrm{km}$ is exceeded.

- If the particles are separated into nucleation particles $(D p<30 \mathrm{~nm}$ ) and accumulation particles (Dp $>30 \mathrm{~nm})$, there is a decrease of the former. The reason lies in the coagulation of nucleation particles across the DPF due to fact that thermal inertia has at the DPF outlet channels, cooling down the exhaust gases. Hence, the primary particles undergoes a diameter growth becoming part of the accumulation particles mode. This is a clear advantage because recent studies show that smaller particles are the most harmful to human health $[44,45]$ even they are not regulated.

\section{Acknowledgements}

This work has been partially supported by the spanish Ministerio de Ciencia e Innovación through grant number DPI2010-20891-C02-02. The authors would like to thank José Ramón Serrano for his help.

\section{References}

[1] C. Pope, D. Dockery, Health effects of fine particulate air pollution: lines that connect, Journal of the Air and Waste Management Association, 56(6) (2006) 709-742.

[2] G. Oberdörster, M. J. Utell, Ultrafine particles in the urban air: to the respiratory track and beyond, Environmental Health Perspectives 110(8) (2002) A440-A441.

[3] V. Bermúdez, J. M. Luján, B. Pla, W. G. Linares, Effects of low pressure exhaust gas recirculation on regulated and unregulated gaseous emissions during NEDC in a light-duty diesel engine, Energy 36(1) (2011) 5655-5665. 
[4] W. Knetch, Diesel engine development in view of reduce emission standars, Energy 33(2) (2008) $264-271$.

[5] X. Lu, Y. Qian, Z. Yang, D. Han, J. Ji, X. Zhou, Z. Huang, Experimental study on compound HCCI (homogenous charge compression ignition) combustion fueled with gasoline and diesel blends, Energy 64(1) (2014) 707-718.

[6] J. Galindo, J.M. Lujan, J.R. Serrano, V. Dolz, Design of an exhaust manifold to improve transient performance of a high-speed turbocharged diesel engine, Applied Thermal Engineering, 28(8) (2004) 863-875.

[7] Z. G. Liu, V. N. Vasys, D. B. Kittelson, Nuclei-mode particulate emissions and their response to fuel sulfur content and primary dilution during transient operations of old and modern diesel engines, Environmental Science \& Technology 41(18) (2007) 6479-6483.

[8] A. G. Konstandopoulos, M. Kostoglou, N. Vlachos, E. Kladopoulou, Advances in the science and technology of diesel particulate filter simulation, Advances in Chemical Engineering 33 (2007) 284-294.

[9] J. C. Stetter, D. E. Foster, J. J. Schauer, Modern diesel particulate matter measurements and the application of lessons learned to 2007 levels and beyond, SAE Technical Paper 2005-01-0194.

[10] K. Tsuneyoshi, K. Yamamoto, A study on the cell structure and the performances of wall-flow diesel particulate filter, Energy 48(1) (2012) 492-499.

[11] G. Mazzarella, F. Ferraraccio, M. V. Prati, S. Annunziata, A. Biancod, A. Mezzogiornoe, G. Liguorif, I. F. Angelilloe, M. Cazzolag, Effects of diesel exhaust particles on human lung epithelial cells: An in vitro study, Respiratory Medicine 101(6) (2007) 1155-1162.

[12] 2008/692/EC, Implementing and amending regulation (EC) n.715/2007 of the european parliament and of the council of 20 June 2007 on type-approval of motor vehicles with respect to emissions from light passenger and commercial vehicles (EURO 5 and EURO 6) and on access to vehicle repair and maintenance information. Official Journal of the European Union, June 2007.

[13] M. G. Khair, A review of diesel particulate filter technologies, SAE Technical Paper 2003-01-2303.

[14] K. Ogyu, K. Ohno, S. Hong, T. Komori, Ash storage capacity enhancement of diesel particulate filter, SAE Technical Paper 2004-01-949.

[15] J.R. Serrano, F. J. Arnau, P. Piqueras, O. García-Afonso, Packed bed of spherical particles approach for pressure drop prediction in wall-flow DPFs (diesel particulate filters) under soot loading conditions, Energy 58(1) (2013) 644-654.

[16] J. Galindo, J.R. Serrano, P. Piqueras, O. García-Afonso, Heat transfer modelling in honeycomb wall-flow diesel particulate filters, Energy 43(1) (2012) 201-213.

[17] S. Lorentzou, C. Pagkoura, A. G. Konstandopoulos, J. Boettcher, Advanced catalyst coatings for diesel particulate filters, SAE technical paper 2008-01-0843.

[18] M. C. Law, A. Clarke, C. P. Garner, The effects of soot properties on the regeneration behaviour of wall-flow diesel particulate filters, J. Automobile Engineering 218(12) (2004) 1513-1524.

[19] F. Payri, J. M. Desantes, J. Galindo, J. R. Serrano, Exhaust manifold of a turbo-charged reciprocating internal combustion engine, Patent Application Publication WO 2010/092201 A1 (2010).

[20] R. E. Windsor, K. J. Baumgard, Internal combustion engine with dual particulate traps ahead of turbocharger, Patent Application Publication, US 2009/0151328 A1, United States (Febraury 2009).

[21] M. Takashi, N. Hideo, I. Toshio, O. Kazuya, I. Seiji, Exhaust gas recirculating system, JP 2005/232996 (2005).

[22] B. Carberry, G. Grasi, S. Guerin, F. Jayat, R. Konieczny, Pre-Turbocharger Catalyst - Fast catalyst light-off evaluation, SAE Technical Paper 2005-01-2142.

[23] M. N. Subramanian, V. Joergl, P. Keller, O. Weber, T. Toyoshima, C. D. Vogt, Feasibility assessment of a pre-turbo aftertreatment system with 1D modeling approach, SAE Technical Paper 2009-01-1276.

[24] V. Bermúdez, J. R. Serrano, P. Piqueras, O. García-Afonso, Assesment by means of gas dynamic modeling of a pre-turbo DPF configuration in a turbocharged HSDI diesel engine under full-load transient operation, Journal of Automobile Engeneering, 225(9) (2011) 1134-1155.

[25] F. Payri, J. R. Serrano, P. Piqueras, O. García-Afonso, Analysis of heavy-duty turbocharged diesel engine response under cold transient operation with a pre-turbo aftertreatment exhaust manifold configuration, International Journal of Engine Research, 0(0) (2012) 1-13. DOI: $10.1177 / 1468087412457670$

[26] A. Martyr, M. A. Plint, Engine Testing: Theory and Practice, Oxford: Butterworth-Heinemann, 1999. 
[27] J. Galindo, V. Bermúdez, J. R. Serrano, J. J. López, Cycle to cycle diesel combustion characterisation during engine transient operation, SAE Technical Report 2001-01-3262.

[28] T. Johnson, R. Caldow, A. Pocher, A. Mirme, D. B. Kittelson, A new electrical mobility particle sizer spectrometer for engine exhaust particle measurements, SAE Technical Report 2004-01-1341.

[29] J. M. Desantes, V. Bermúdez, S. Molina, W. G. Linares, Methodology for measuring exhaust aerosol size distributions using an engine test under transient operating conditions, Measurement Science and Technology 22(11) (2011) 115101. DOI:10.1088/0957-0233/22/11/115101

[30] Dekati fine smart particle sampler FPS-4000. User manual.

[31] D. Kim, M. Gautam, D. Gera, Parametric studies on the formation of diesel particulate matter via nucleation and coagulation modes, Journal of Aerosol Science 33(12) (2002) 1609-1621.

[32] I. S. Abdul-Khalek, D. B. Kittelson, B. R. Graskow, Q. Wei, F. Bear, Diesel exhaust particle size: measurement issues and trends, SAE International 980525.

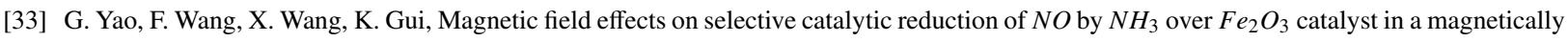
fluidized bed, Energy 35(5) (2010) 2295-2300.

[34] S. S. Verma, Parametric studies on $\mathrm{N}_{2} \mathrm{O}$ formation and destruction mechanisms, Energy Conversion and Management 43(13) (2002) 17371746.

[35] J. M. Desantes, V. Bermúdez, J. V. Pastor, E. Fuentes, Methodology for measuring exhaust aerosol size distributions from heavy duty diesel engines by means of a scanning mobility particle sizer, Measurement Science and Technology 15(10) (2004) $2083-2098$.

[36] J. Galindo, J.M. Lujan, J.R. Serrano, V. Dolz, Description of a heat transfer model suitable to calculate transient processes of turbocharged diesel engines with one-dimensional gas-dynamic codes, Applied Thermal Engineering, 26(1) (2006) 66-76.

[37] M. Lapuerta, F. J. Martos, J. M. Herreros, Effect of engine operating conditions on the size of primary particles composing Diesel soot agglomerates, Journal of Aerosol Science 38(4) (2007) 455-466.

[38] J. L. Katz, Condensation of a supersaturated vapor. i. the homogeneous nucleation of the n-Alkanes, The Journal of Chemical Physics 52 (1970) 4733 .

[39] C. Beatrice, S. Di Iorio, C. Guido, P. Napolitano,Detailed characterization of particulate emissions of an automotive catalyzed DPF using actual regeneration strategies, Experimental Thermal and Fluid Science 39(0) (2012) 45-53.

[40] E. Ohara, Y. Mizuno, Y. Miyairi, T. Mizunati, K. Yuuki, Y. Noguchi, T. Hiramatsu, M. Makino, A. Takahashi, S. H., Filtration behavior of diesel particulate filters (1), SAE Technical Paper 2007-01-0921.

[41] A. Abánades, C. Rubbia, D. Salmieri, Technological challenges for industrial development of hydrogen production based on methane cracking, Energy 46(1) (2012) 359-363.

[42] F. Payri, V. Bermúdez, B. Tormos, W. G. Linares, Hydrocarbon emissions speciation in diesel and biodiesel exhausts, Atmospheric Environment 43(6) (2009) 1273-1279.

[43] T. Li, H. Izumi, T. Shudo, H. Ogawa, Characteristics of unregulated toxic emissions from ultrahigh egr low temperature diesel combustion and effects of exhaust catalyst, JSME Trans. B 73 (2007) 1129-34.

[44] Z. Zheng, C. J. Kent, Z. Liu, T. D. Durbin, S. Hu, T. Huai, D. B. Kittelson, H. S. Jung, Investigation of solid particle number measurement: Existence and nature of sub-23 nm particles under pmp methodology, Journal of Aerosol Science 42(12) (2011) 883-897.

[45] A. D. Kappos, P. Bruckmann, T. Eikmann, N. Englert, U. Heinrich, P. Hppe, E. Koch, G. H. Krause, W. G. Kreyling, K. Rauchfuss, P. Rombout, V. Schulz-Klemp, W. R. Thiel, H.-E. Wichmann, Health effects of particles in ambient air, International Journal of Hygiene and Environmental Health 207(4) (2004) 399-407. 


\section{Nomenclature}

$\begin{array}{ll}\text { Subscripts } & \\ \text { inlet } & \text { inlet channel } \\ \text { outlet } & \text { outlet channel } \\ \text { ac } & \text { accumulated mass }\end{array}$

Abbreviations

$\begin{array}{ll}\text { AF } & \text { Air to fuel ratio } \\ \text { CRT } & \text { Continuous regeneration trap } \\ \text { DOC } & \text { Diesel oxidation catalyst } \\ \text { DR } & \text { Dilution ratio } \\ \text { DPF } & \text { Diesel particulate filter } \\ \text { ECU } & \text { Electronic control unit } \\ \text { EEPS } & \text { Engine exhaust particle sizer } \\ \text { EGR } & \text { Exhaust gas recirculated } \\ \text { EUDC } & \text { Extra urban driving cycle } \\ \text { FPS } & \text { Fine particle sampler } \\ \text { FTIR } & \text { Fourier transform infrared spectroscopy } \\ \text { GMD } & \text { Geometric mean diameter } \\ \text { HSDI } & \text { High speed direct injection } \\ \text { NEDC } & \text { New european driving cycle } \\ \text { SCR } & \text { Selective catalytic reduction } \\ \text { SOI } & \text { Start of injection } \\ \text { UDC } & \text { Ultra low sulfur Diesel } \\ \text { USLD } & \end{array}$

\section{List of Tables}

- Table 1.- Engines main characteristics.

- Table 2.- Aftertreatment characteristics.

- Table 3.- Fuel properties.

- Table 4.- Technical data of piezoresistive pressure sensors.

- Table 5.- Steady-state operating points. Main parameters.

- Table 6.- Regulated pollutants emission. 


\section{List of Figures}

- Figure 1.- Experimental setup for the evaluation of the aftertreatment response.

- Figure 2.- Representation in the NEDC map of the operating points selected for the evaluation of the aftertreatment response.

- Figure 3.- Particle evolution at dilution system. Theoretical phase-diagram used in the methodology for measuring particle distribution size [29].

- Figure 4.- Steady-state operating points. Control variables analyzed.

- Figure 5.- Nitrogen oxides emission at steady-state operating conditions. A) Total nitrogen oxides (NOx). B) Nitrogen dioxide $\left(\mathrm{NO}_{2}\right)$. C) Nitrogen monoxide $(\mathrm{NO})$. Pre-turbo vs. Post-turbo aftertreatment configuration.

- Figure 6.- Carbon monoxide emission at steady-state operating conditions. Pre-turbo vs. Post-turbo aftertreatment configuration.

- Figure 7.- Light hydrocarbons ( $<7$ Carbon atoms) at steady-state operating conditions. Methene $\left(\mathrm{CH}_{4}\right)$ and iso-butene (iso $-\mathrm{C}_{4} \mathrm{H}_{8}$ ). Pre-turbo vs. Post-turbo aftertreatment configuration.

- Figure 8.- Particle distribution size upstream the DPF at steady-state operating conditions. Pre-turbo vs. Post-turbo aftertreatment configuration.

- Figure 9.- Temperature drop along the exhaust system. Pre-turbo vs. Post-turbo configuration.

- Figure 10.- DPF inlet particle emission analysis at steady-state operation conditions. A) Particle concentration. B) Percentage of cores. C) Geometric mean diameter (GMD). Pre-turbo vs. Post-turbo aftertreatment configuration.

- Figure 11.- Nuclei-mode formation.

- Figure 12.- DPF filtration efficiency (FE) at steady-state operating conditions. Pre-turbo vs. Post-turbo aftertreatment configuration.

- Figure 13.- Nitrogen oxides evaluation during NEDC. A) $N O x$ upstream DOC. B) $N O x$ downstream DOC. C) $N O$ upstream DOC. D) $\mathrm{NO}$ downstream DOC. E) $\mathrm{NO}_{2}$ upstream DOC. F) $\mathrm{NO}_{2}$ downstream DOC. Pre-turbo vs. Post-turbo aftertreatment configuration.

- Figure 14.- $\mathrm{NH}_{3}, \mathrm{SO}_{2}$ and $\mathrm{N}_{2} \mathrm{O}$ emission during NEDC asessed in a pre-turbo aftertreatment configuration. A) $\mathrm{NH}_{3}$ emission. B) $\mathrm{SO}_{2}$ emission. C) $\mathrm{N}_{2} \mathrm{O}$ emission.

- Figure 15.- Carbon monoxide and total hydrocarbons evaluation during a NEDC. A) CO emission. B) THC emission. Pre-turbo vs. Post-turbo aftertreatment configuration.

- Figure 16.- Light HC ( $<7$ Carbon atoms) evaluation at DOC inlet during NEDC. A) Methane $\left(\mathrm{CH}_{4}\right)$. B) Ethylene $\left(\mathrm{C}_{2} \mathrm{H}_{4}\right)$. C) Propene $\left(\mathrm{C}_{3} \mathrm{H}_{6}\right)$. D) Iso-butene $\left(i s o-\mathrm{C}_{3} H_{6}\right)$. E) Benzene $\left(\mathrm{C}_{6} \mathrm{H}_{6}\right)$. F) Total light HC. Pre-turbo vs. Post-turbo aftertreatment configuration.

- Figure 17.- Light HC (<7 Carbon atoms) evaluation at DOC during NEDC. Pre-turbo vs. Post-turbo aftertreatment configuration. 
- Figure 18.- Dilution ratio during NEDC. A) Dilution ratio upstream the DPF. B) Dilution ratio downstream the DPF. Pre-turbo vs. Post-turbo aftertreatment configuration.

- Figure 19.- Particle emission evaluation during NEDC. A) Total particles at DPF inlet. B) Total particles at DPF outlet. C) Accumulation particles at DPF inlet. D) Accumulation particles at DPF outlet. E) Nucleation particles at DPF inlet. F) Nucleation particles at DPF outlet. Pre-turbo vs. Post-turbo aftertreatment configuration.

- Figure 20.- Particle evolution at the dilution system. Pre-turbo vs. Post-turbo aftertreatment configuration. 
Table 1: Engine's main characteristics.

\begin{tabular}{ll}
\hline \hline Type & 4-cycle \\
Displacement & $1997\left[\mathrm{~cm}^{3}\right]$ \\
Diameter & $85[\mathrm{~mm}]$ \\
Stroke & $88[\mathrm{~mm}]$ \\
Number of cylinders & $4[-]$ \\
Valves by cilinder & $4[-]$ \\
Compression ratio & $18: 1[-]$ \\
Maximun power & $100[\mathrm{~kW}]$ at $4000 \mathrm{rpm}$ \\
Maximun torque & $320[\mathrm{Nm}]$ at $1750 \mathrm{rpm}$ \\
Spray cone angle & $140\left[{ }^{\circ}\right]$ \\
Nozzle holes & $6 \times 146[\mu \mathrm{m}]$ \\
\hline \hline
\end{tabular}

Table 2: Aftertreatment characteristics.

\begin{tabular}{llll}
\hline \multicolumn{1}{c}{ DOC } & & \multicolumn{2}{c}{ DPF } \\
\hline Length & $0.105[\mathrm{~m}]$ & Length & $0.165[\mathrm{~m}]$ \\
Diameter & $0.145[\mathrm{~m}]$ & Diameter & $0.135[\mathrm{~m}]$ \\
Volume & $1.73[\mathrm{~L}]$ & Volume & $2.36[\mathrm{~L}]$ \\
Cell density & $400[\mathrm{cpsi}]$ & Cell density & $200[\mathrm{cpsi}]$ \\
Cell size & $0.94[\mathrm{~mm}]$ & Cell size & $1.47[\mathrm{~mm}]$ \\
Wall thickness & $0.33[\mathrm{~mm}]$ & Wall thickness & $0.32[\mathrm{~mm}]$ \\
Number of channels & $10240[-]$ & Number of channels & $4470[-]$ \\
Catalytic surface & $4.04\left[\mathrm{~m}^{2}\right]$ & Filtration surface & $2.17\left[\mathrm{~m}^{2}\right]$ \\
& & Permeability & $3.175 \times 10^{-13}[\mathrm{~mm}]$ \\
\hline \hline
\end{tabular}




\begin{tabular}{ll}
\multicolumn{2}{c}{ Table 3: Fuel properties. } \\
\hline \hline Cetane number & $51.6[-]$ \\
Viscosity at $40^{\circ} \mathrm{C}$ & $2.46\left[\mathrm{~mm}^{2} / \mathrm{s}\right]$ \\
Density at $15^{\circ} \mathrm{C}$ & $0.843[\mathrm{~kg} / \mathrm{l}]$ \\
Lower heating value & $42.055[\mathrm{MJ} / \mathrm{kg}]$ \\
Sulfur content & $6.6[\mathrm{ppm}]$ \\
Water content & $96[\mathrm{ppm}]$ \\
\hline \hline
\end{tabular}

\begin{tabular}{ll} 
Table 4: Technical data of piezoresistive pressure sensors. \\
\hline \hline Range & $0-5[\operatorname{bar}(a b s)]$ \\
Overload & $12.5[\operatorname{bar}(a b s)]$ \\
Sensitivity & $25[\mathrm{mV} /$ bar $/ m A]$ \\
Linearity & $\leq 0.1[\% \mathrm{FSO}]$ \\
Temperature range & $0-140\left[{ }^{\circ} \mathrm{C}\right]$ \\
\hline \hline
\end{tabular}

Table 5: Steady-state operating points. Main parameters.

\begin{tabular}{lcccccc}
\hline \hline Point & Speed & Torque & Load & SOI & EGR & Particle mode \\
\hline \hline F & {$[\mathrm{rpm}]$} & {$[\mathrm{N} . \mathrm{m}]$} & {$[\%]$} & {$\left[{ }^{\circ}\right]$} & {$[\%]$} & {$[-]$} \\
$\mathrm{J}$ & 1370 & 15 & 7 & -1.62 & 48.5 & Bimodal \\
$\mathrm{K}$ & 1960 & 16 & 8 & -0.40 & 36 & Bimodal \\
$\mathrm{L}$ & 1660 & 104 & 21 & -3.54 & 12.5 & Accumulation \\
$\mathrm{Q}$ & 2240 & 89 & 25 & -1.2 & 12.85 & Accumulation \\
\hline \hline
\end{tabular}

Table 6: Regulated pollutants emission.

\begin{tabular}{ccccc}
\hline \hline Pollutant & EURO 4 limit & EURO 5 limit & Post-turbo & Pre-turbo \\
\hline \hline NOx & {$[\mathrm{mg} / \mathrm{km}]$} & {$[\mathrm{mg} / \mathrm{km}]$} & {$[\mathrm{mg} / \mathrm{km}]$} & {$[\mathrm{mg} / \mathrm{km}]$} \\
\hline THC+NOx & 300 & 180 & 188.1 & 197.2 \\
CO & 500 & 230 & 234.5 & 239.1 \\
\hline \hline
\end{tabular}




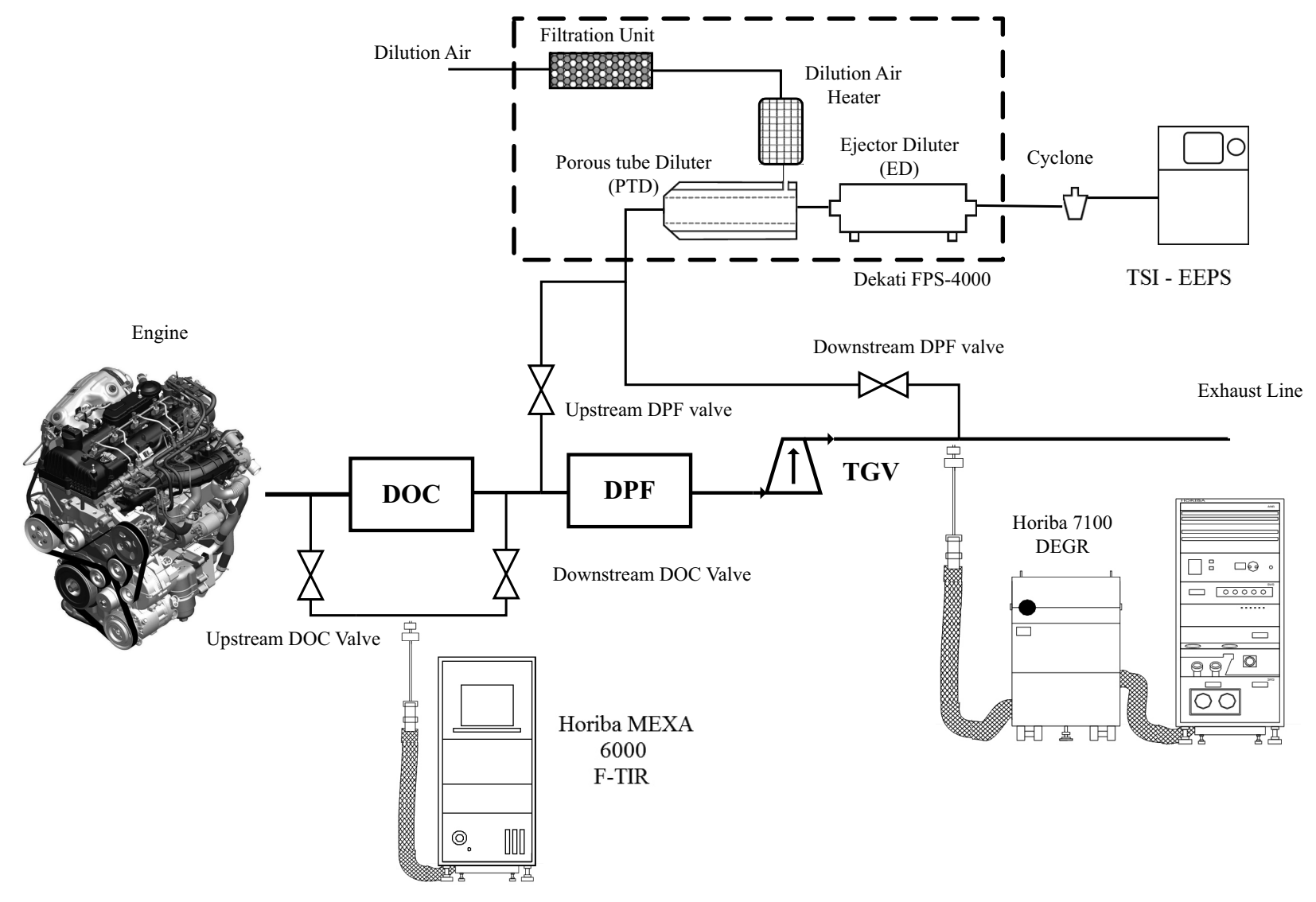

Figure 1: Experimental setup for the evaluation of the aftertreatment response.

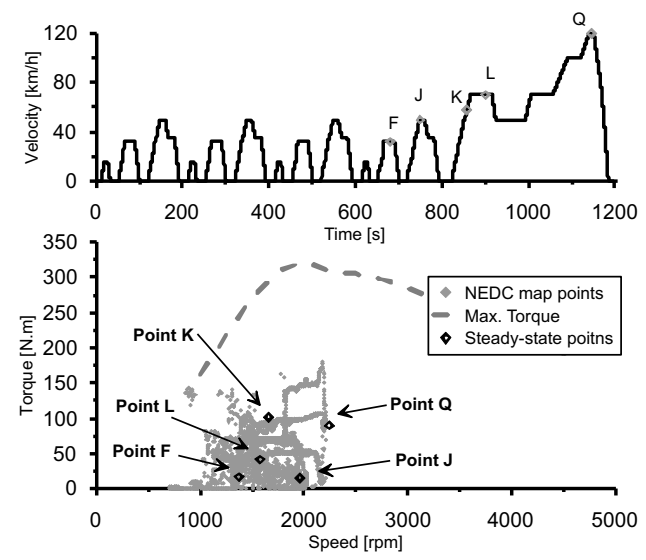

Figure 2: Representation in the NEDC map of the operating points selected for the evaluation of the aftertreatment response. 


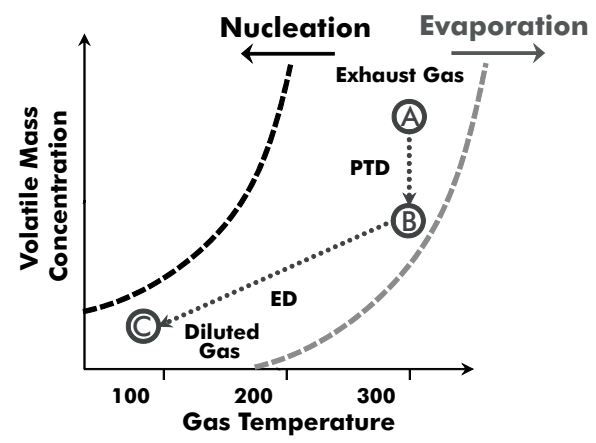

Figure 3: Particle evolution at dilution system. Theoretical phase-diagram used in the methodology for measuring particle distribution size [29].
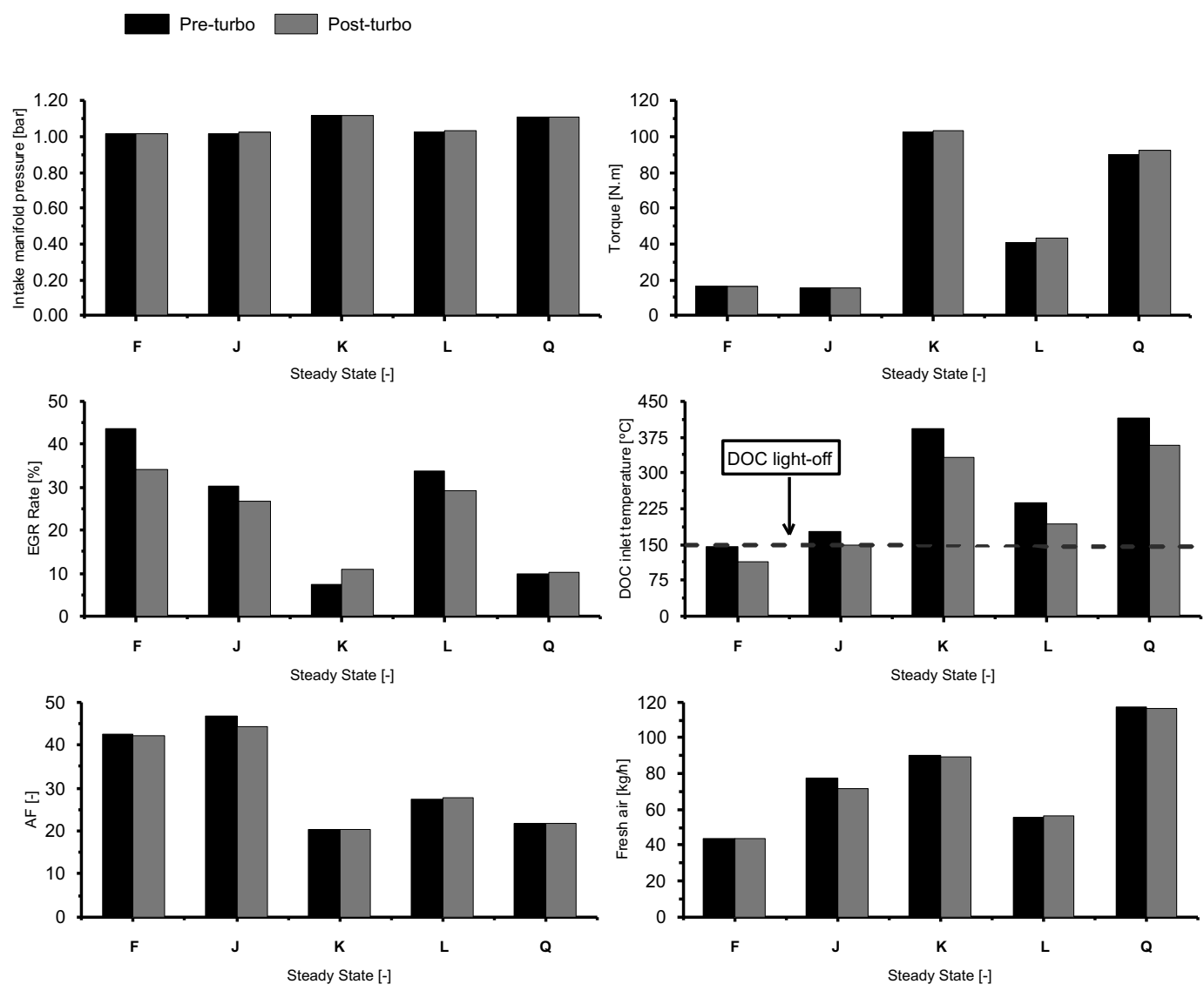

Figure 4: Steady-state operating points. Control variables analyzed. 


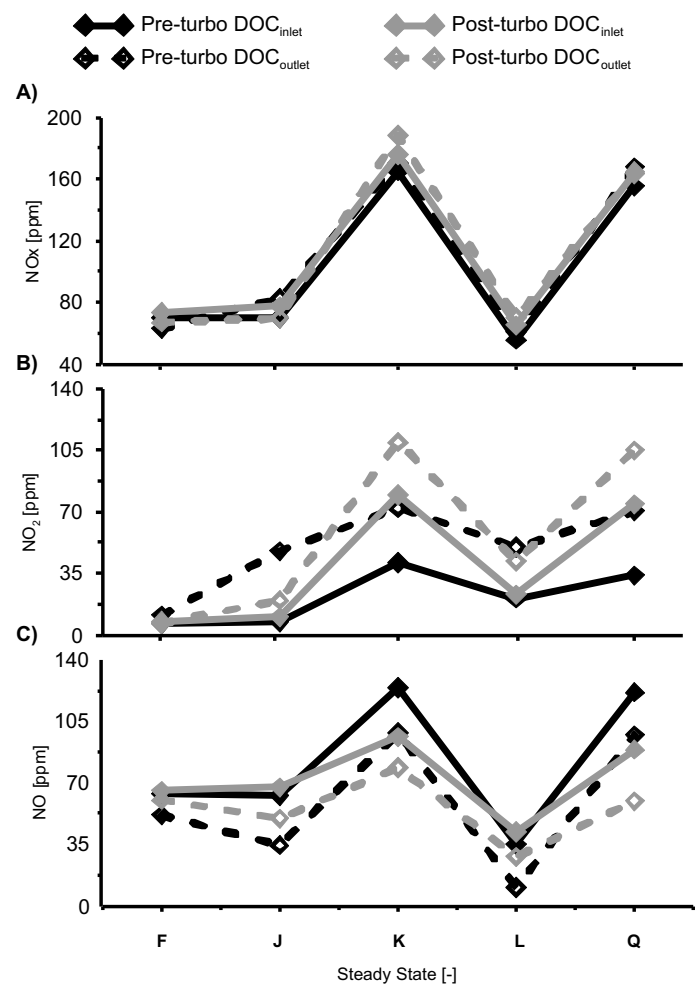

Figure 5: Nitrogen oxides emission at steady-state operating conditions. A) Total nitrogen oxides $(\mathrm{NOx})$. B) Nitrogen dioxide $\left(\mathrm{NO}_{2}\right)$. C) Nitrogen monoxide $(\mathrm{NO})$. Pre-turbo vs. Post-turbo aftertreatment configuration.

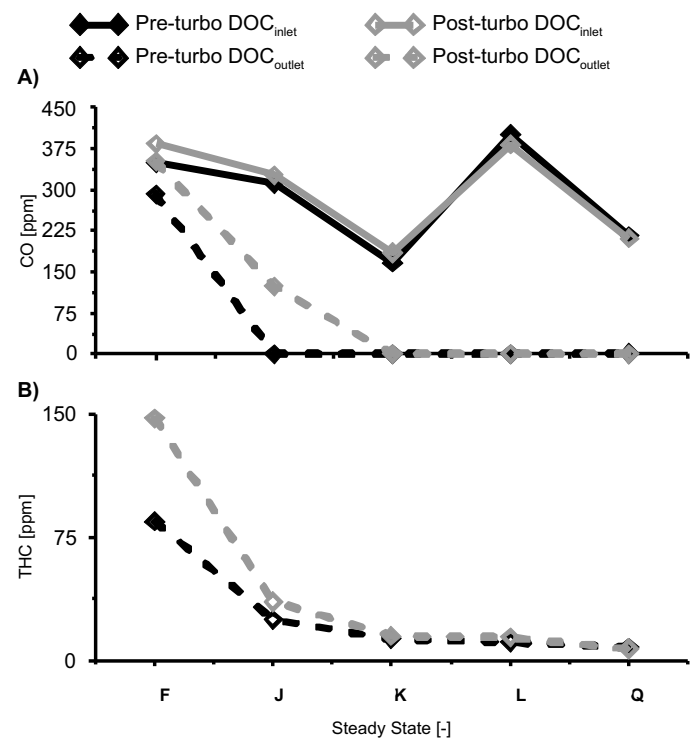

Figure 6: Carbon monoxide and total hydrocarbons emission at steady-state operating conditions. Pre-turbo vs. Post-turbo aftertreatment configuration. 

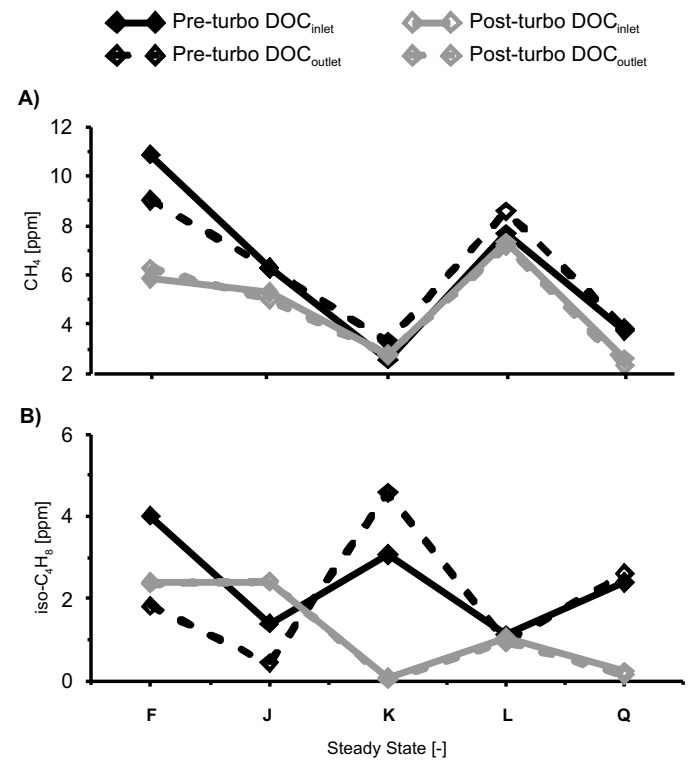

Figure 7: Light hydrocarbons ( $<7$ Carbon atoms) at steady-state operating conditions. Methene $\left(\mathrm{CH}_{4}\right)$ and iso-butene $\left(i s o-\mathrm{C}_{4} \mathrm{H}_{8}\right)$. Pre-turbo vs. Post-turbo aftertreatment configuration.
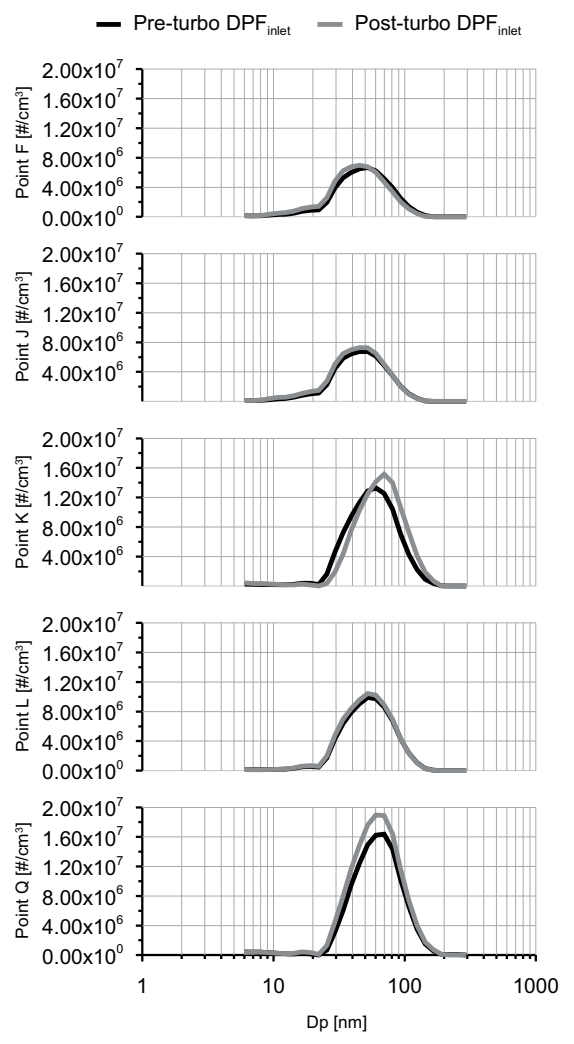

Figure 8: Particle distribution size upstream the DPF at steady-state operating points. Pre-turbo vs. Post-turbo aftertreatment configuration. 

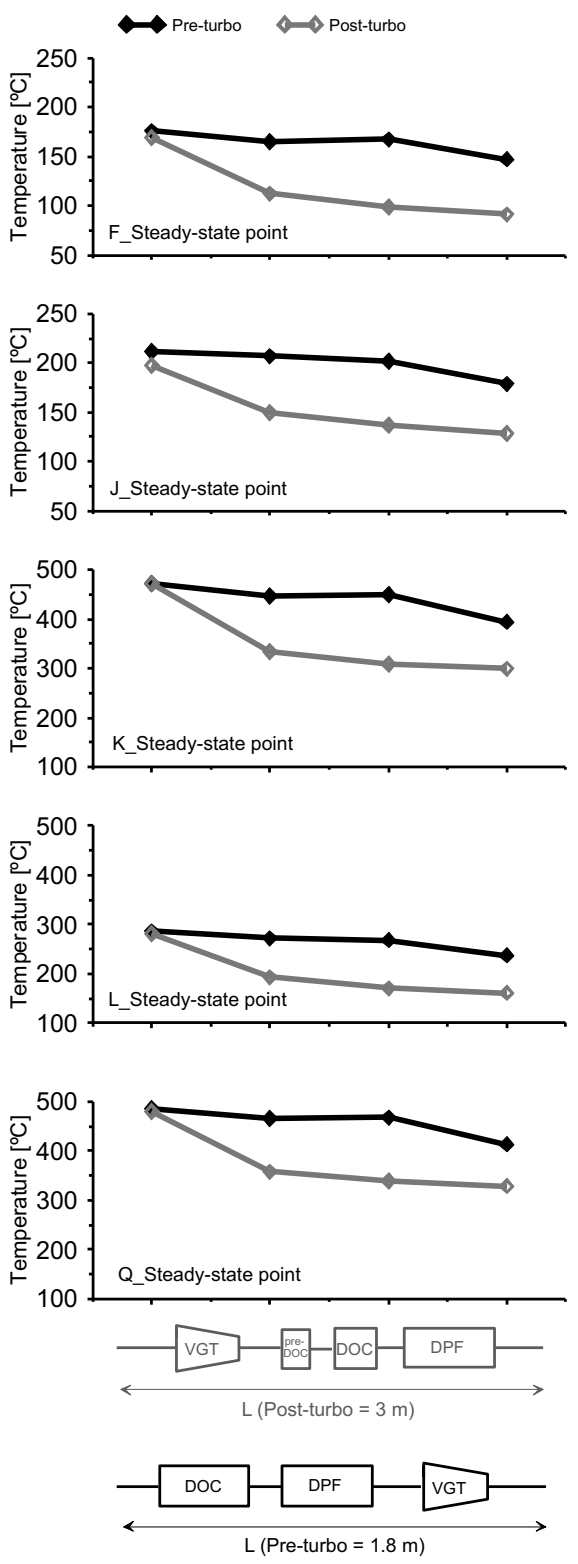

Figure 9: Temperature evolution along the exhaust architechtue at steady-state operating points. Pre-turbo vs. Post-turbo aftertreatment configuration 

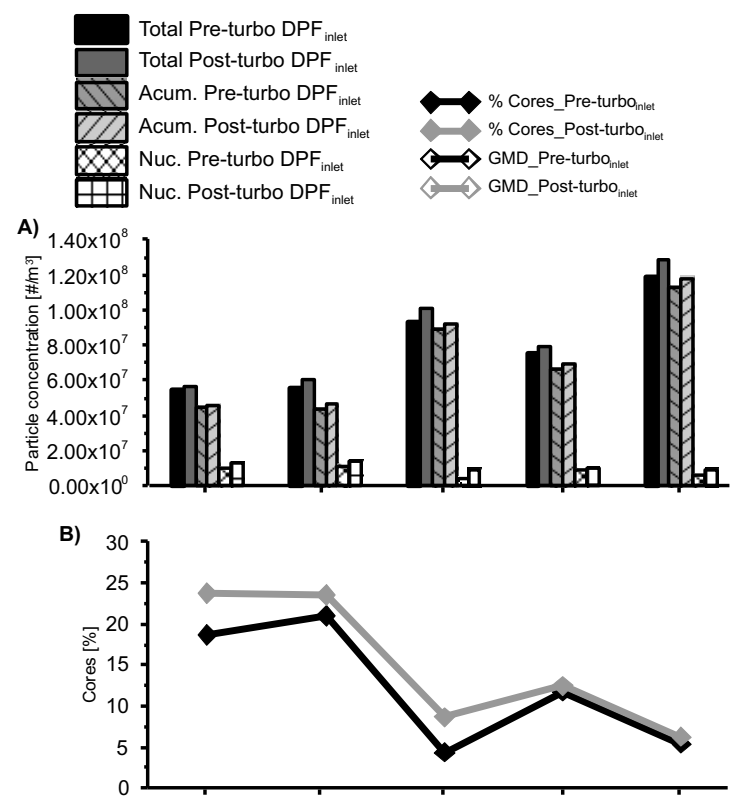

C)

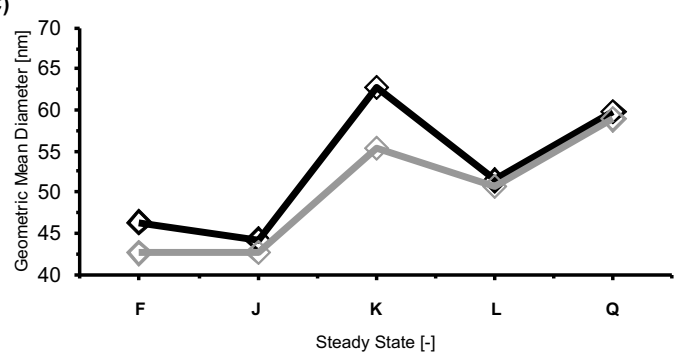

Figure 10: DPF inlet particle emission analysis at steady-state operation conditions. A) Particle concentration. B) Percentage of cores. C) Geometric mean diameter (GMD). Pre-turbo vs. Post-turbo aftertreatment configuration.
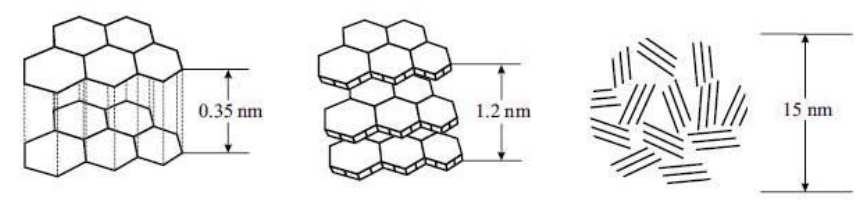

Figure 11: Nuclei-mode formation. 

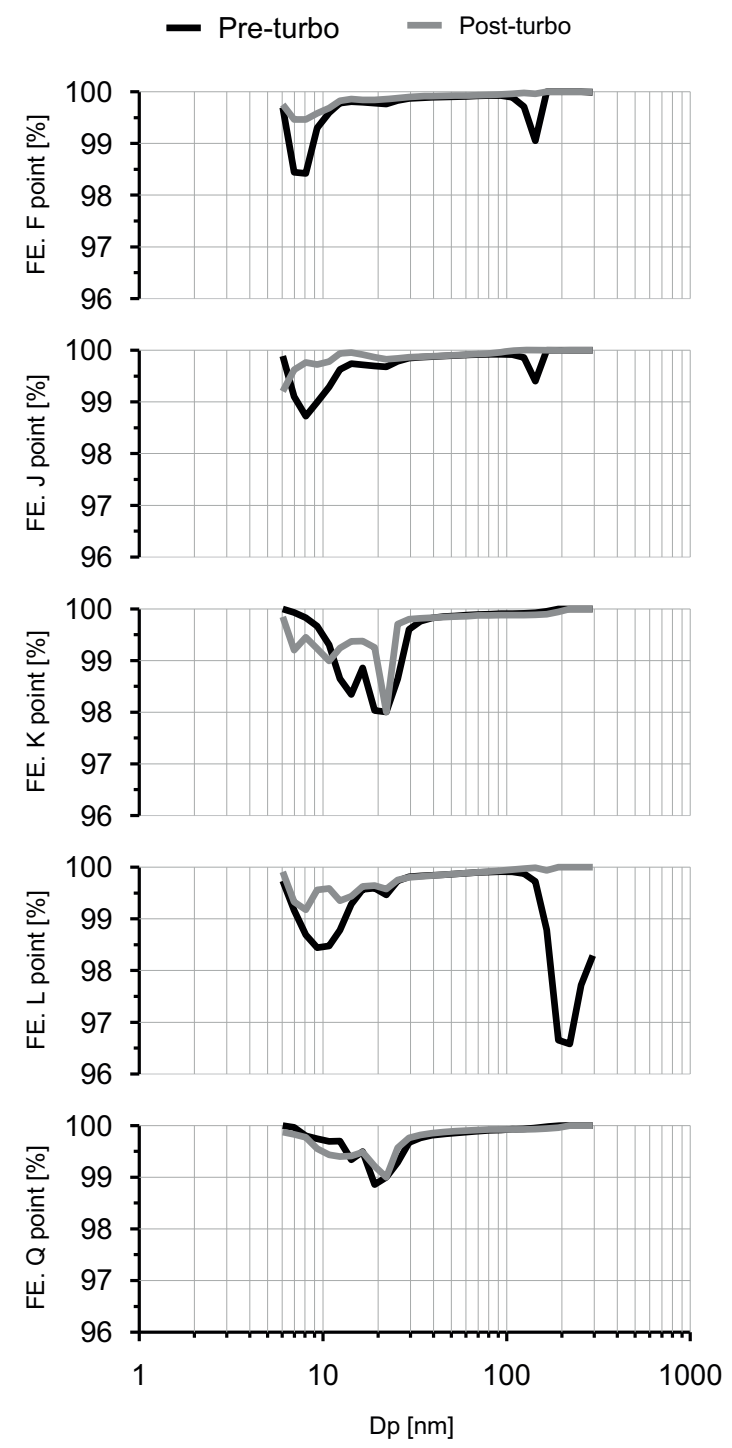

Figure 12: DPF filtration efficiency (FE) at steady-state operating conditions. Pre-turbo vs. Post-turbo aftertreatment configuration. 

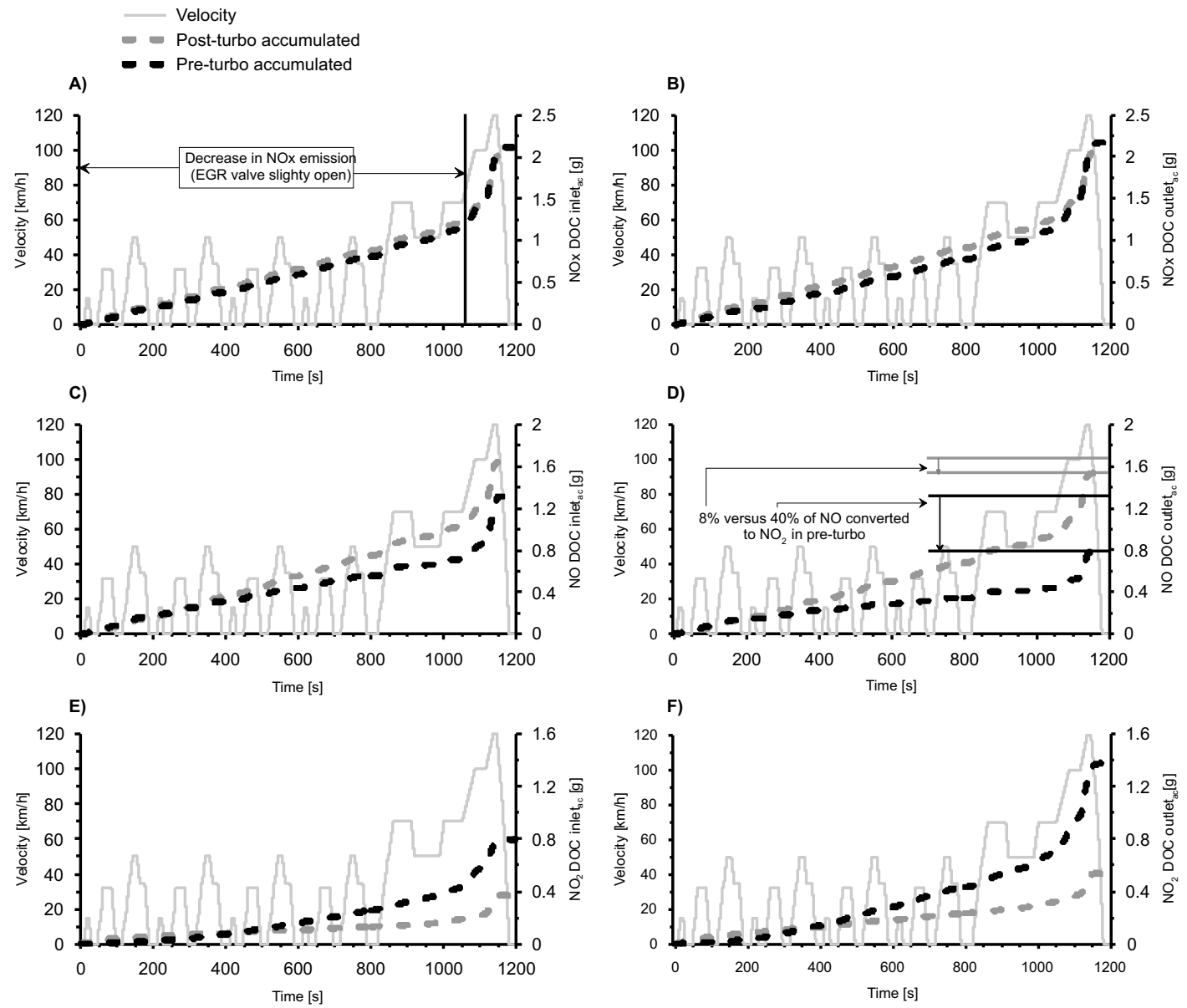

Figure 13: Nitrogen oxides evaluation during NEDC. A) NOx upstream DOC. B) NOx downstream DOC. C) NO upstream DOC. D) NO downstream DOC. E) $\mathrm{NO}_{2}$ upstream DOC. F) $\mathrm{NO}_{2}$ downstream DOC. Pre-turbo vs. Post-turbo aftertreatment configuration. 


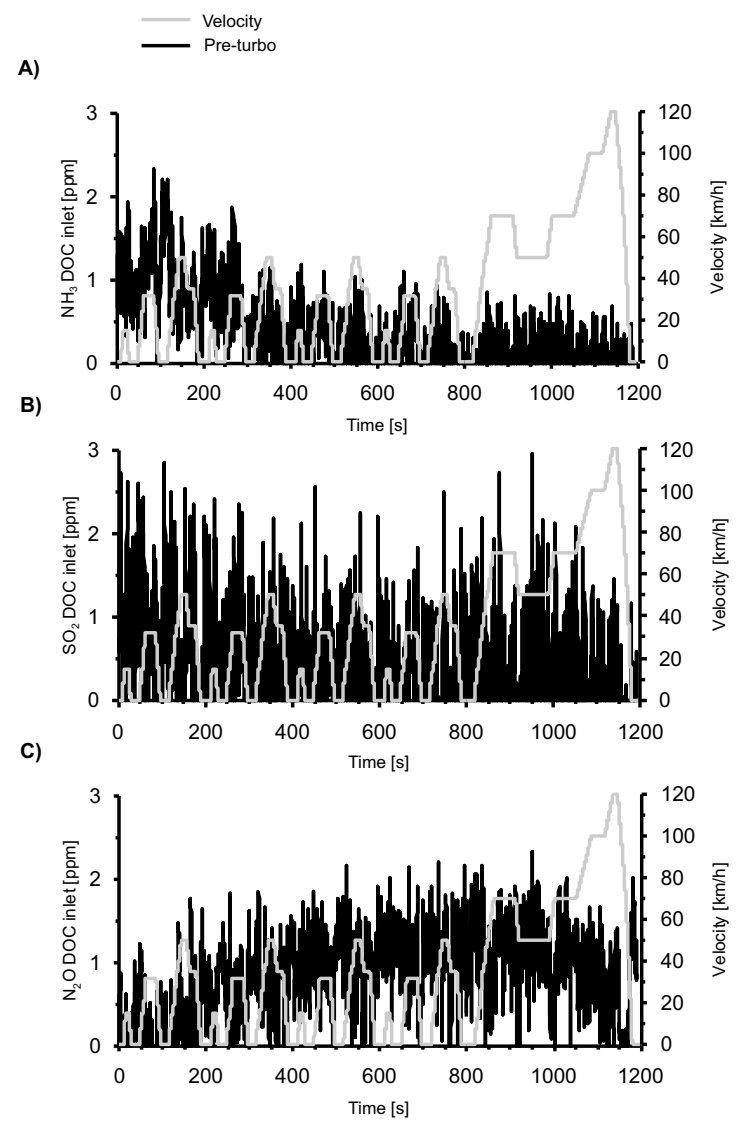

Figure 14: Ammonia $\left(\mathrm{NH}_{3}\right)$, sulfur dioxide $\left(\mathrm{SO}_{2}\right)$ and dinitrogen oxide $\left(\mathrm{N}_{2} \mathrm{O}\right)$ emission during NEDC asessed in a pre-turbo aftertreatment configuration. A) $\mathrm{NH}_{3}$ emission. B) $\mathrm{SO}_{2}$ emission. C) $\mathrm{N}_{2} \mathrm{O}$ emission 


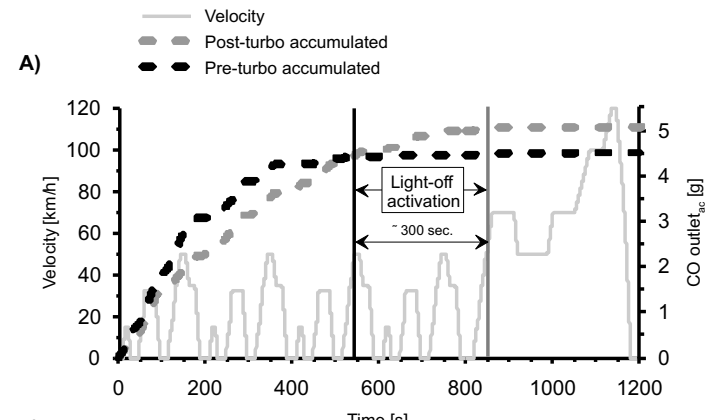

B)

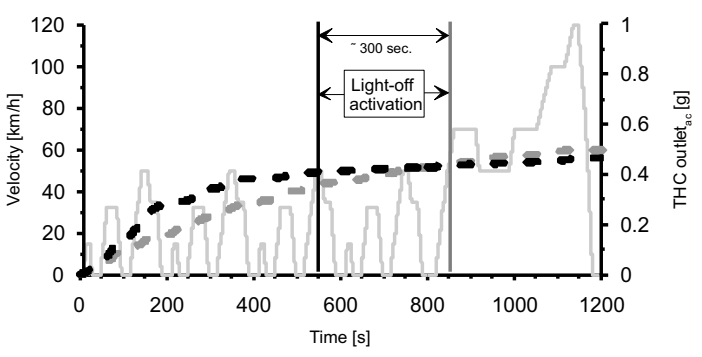

Figure 15: Carbon monoxide and total hydrocarbons evaluation during a NEDC. A) CO emission. B) THC emission. Pre-turbo vs. Post-turbo aftertreatment configuration. 


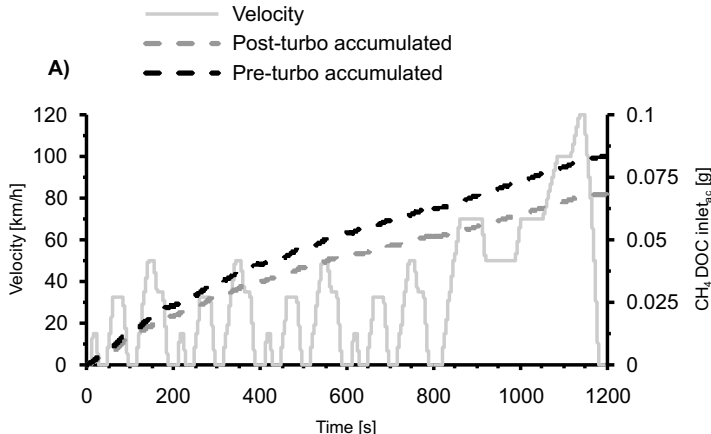

B)

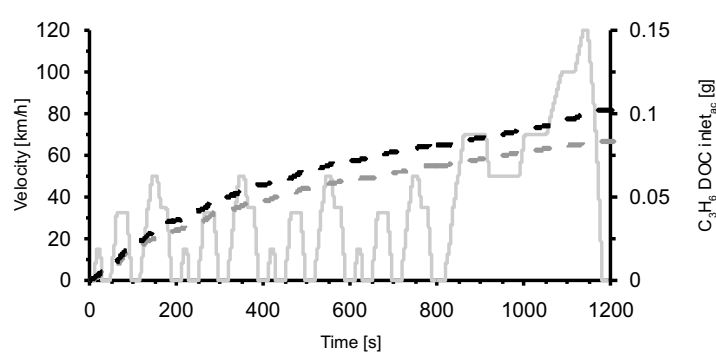

c)

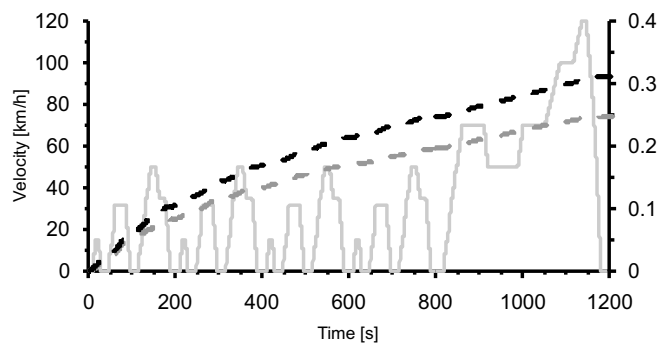

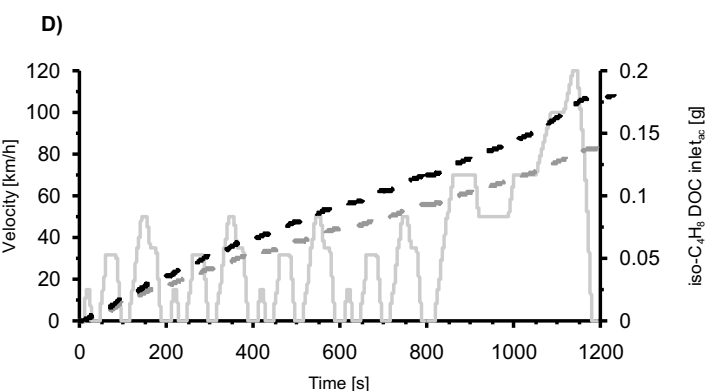

E)

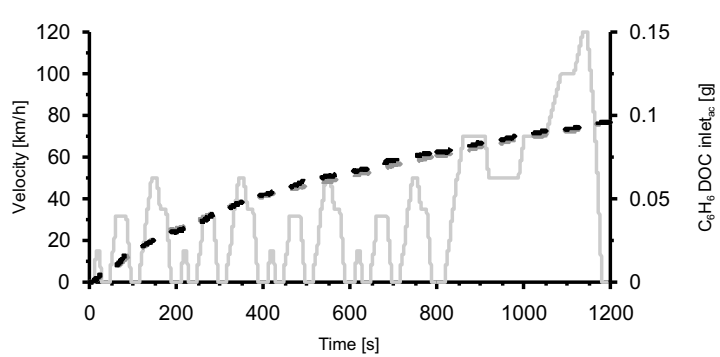

F)

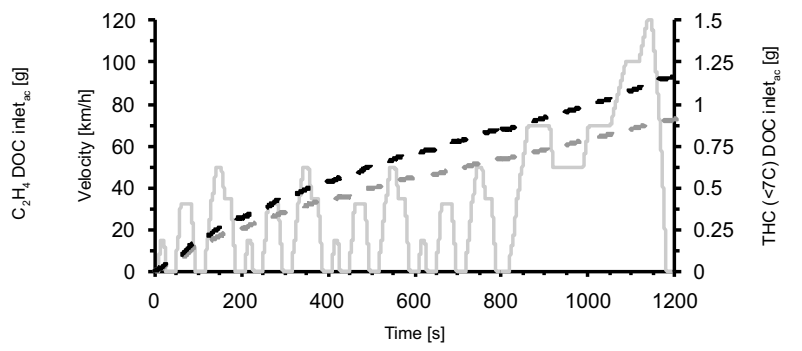

Figure 16: Light HC (<7 Carbon atoms) evaluation at DOC inlet during NEDC. A) Methane $\left(C_{4} H_{4}\right)$ B) Ethylene $\left(C_{2} H_{4}\right)$. C) Propene $\left(C_{3} H_{6}\right)$. D) Iso-butene $\left(\right.$ iso $\left.-\mathrm{C}_{3} \mathrm{H}_{6}\right)$. E) Benzene $\left(\mathrm{C}_{6} \mathrm{H}_{6}\right)$. F) Total light HC. Pre-turbo vs. Post-turbo aftertreatment configuration.

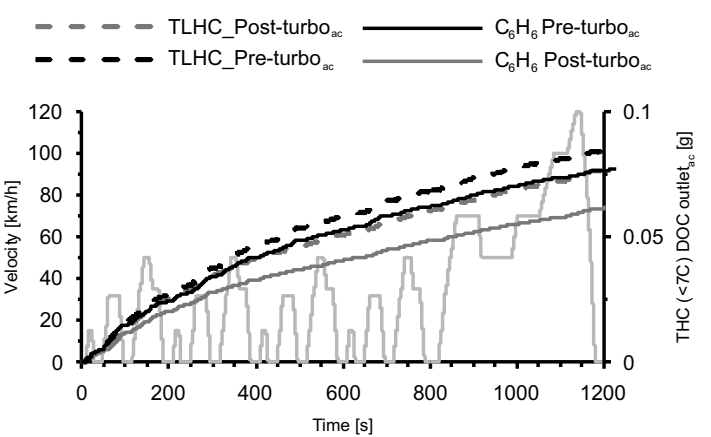

Figure 17: Light HC (<7 Carbon atoms) evaluation at DOC outlet during NEDC. Pre-turbo vs. Post-turbo aftertreatment configuration. 

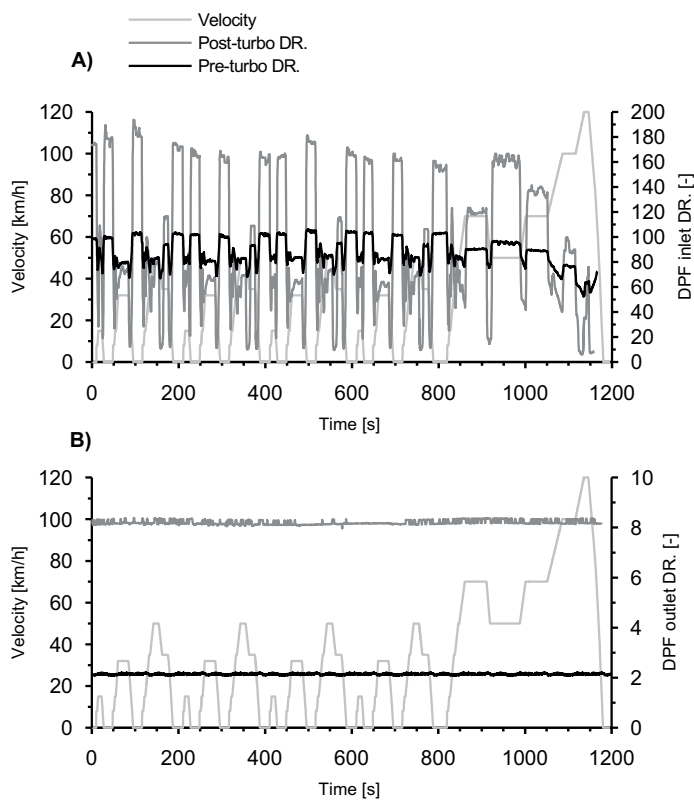

Figure 18: Dilution ratio during NEDC. A) Dilution ratio upstream the DPF. B) Dilution ratio downstream the DPF. Pre-turbo vs. Post-turbo aftertreatment configuration. 

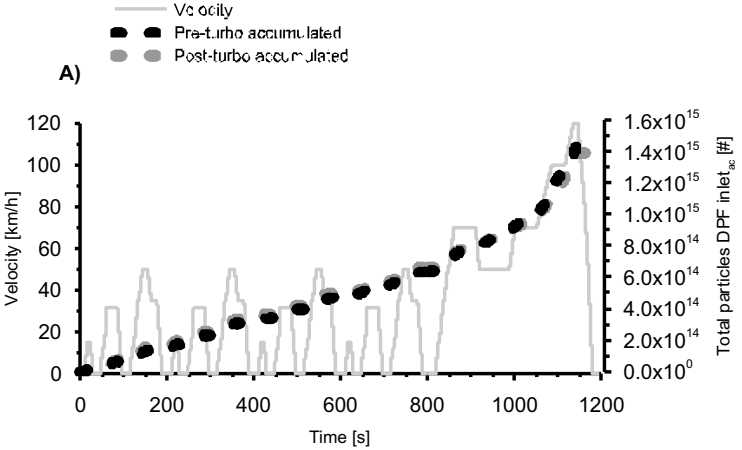

C)

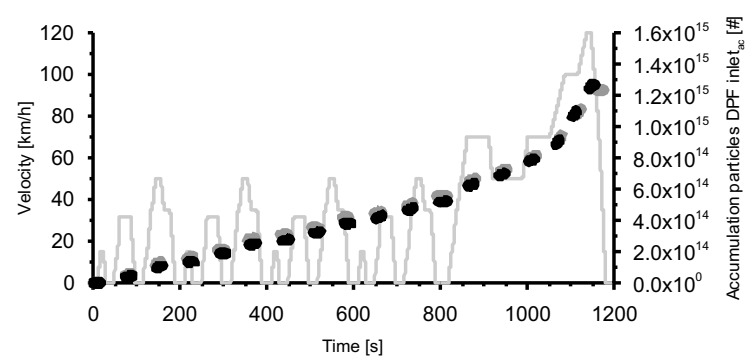

E)

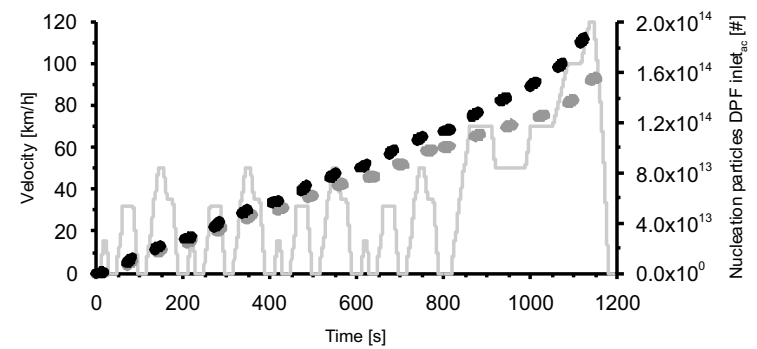

B)

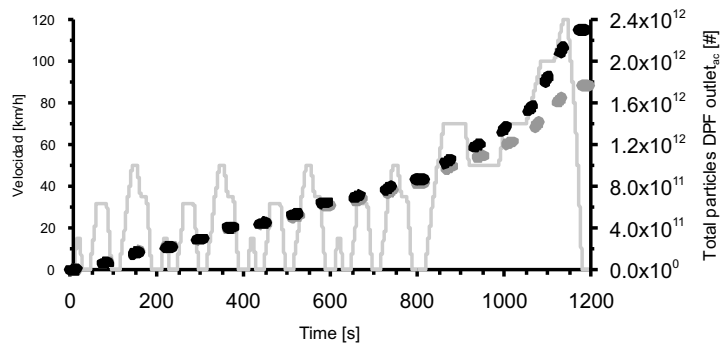

D)

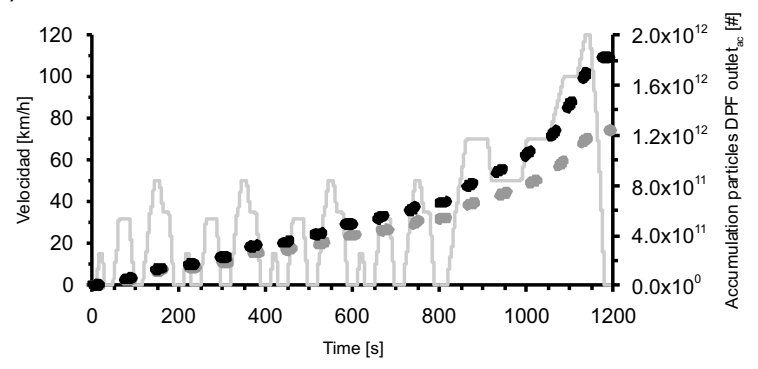

F)

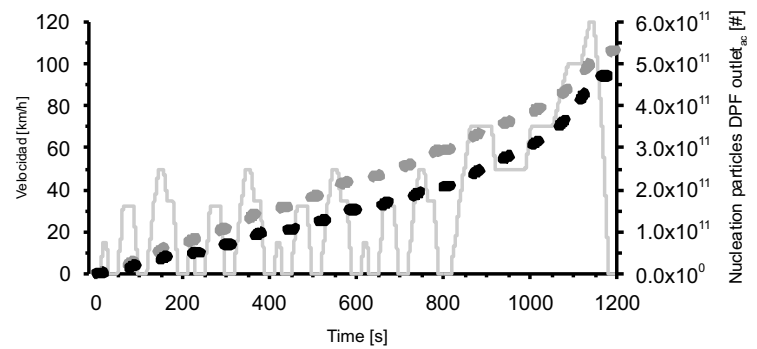

Figure 19: Particle emission evaluation during NEDC. A) Total particles at DPF inlet. B) Total particles at DPF outlet. C) Accumulation particles at DPF inlet. D) Accumulation particles at DPF outlet. E) Nucleation particles at DPF inlet. F) Nucleation particles at DPF outlet. Pre-turbo vs. Post-turbo aftertreatment configuration.

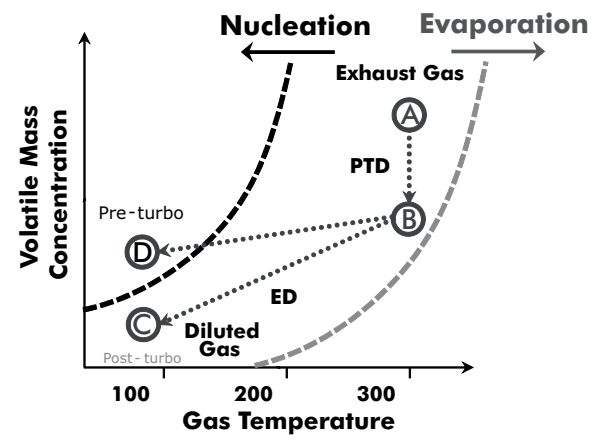

Figure 20: Particle evolution at the dilution system. Pre-turbo vs. Post-turbo aftertreatment configuration. 